\title{
REVIEW
}

\section{Dermoscopy in General Dermatology: A Practical Overview}

Enzo Errichetti $\cdot$ Giuseppe Stinco

Received: July 12, 2016 / Published online: September 9, 2016

(C) The Author(s) 2016. This article is published with open access at Springerlink.com

\section{ABSTRACT}

Over the last few years, dermoscopy has been shown to be a useful tool in assisting the noninvasive diagnosis of various general dermatological disorders. In this article, we sought to provide an up-to-date practical overview on the use of dermoscopy in general dermatology by analysing the dermoscopic differential diagnosis of relatively common dermatological disorders grouped according to their clinical presentation, i.e. dermatoses presenting with erythematous-desquamative patches/plaques (plaque psoriasis, eczematous dermatitis, pityriasis rosea, mycosis fungoides and subacute cutaneous lupus erythematosus), papulosquamous/papulokeratotic dermatoses (lichen planus, pityriasis rosea, papulosquamous sarcoidosis, guttate psoriasis, pityriasis lichenoides chronica, classical

Enhanced content To view enhanced content for this article go to http://www.medengine.com/Redeem/ 2295F06011919714.

E. Errichetti $(\varangle) \cdot$ G. Stinco

Department of Experimental and Clinical Medicine, Institute of Dermatology, University of Udine,

Udine, Italy

e-mail: enzoerri@yahoo.it pityriasis rubra pilaris, porokeratosis, lymphomatoid papulosis, papulosquamous chronic GVHD, parakeratosis variegata, Grover disease, Darier disease and BRAF-inhibitor-induced acantholytic dyskeratosis), facial inflammatory skin diseases (rosacea, seborrheic dermatitis, discoid lupus erythematosus, sarcoidosis, cutaneous leishmaniasis, lupus vulgaris, granuloma faciale and demodicidosis), acquired keratodermas (chronic hand eczema, palmar psoriasis, keratoderma due to mycosis fungoides, keratoderma resulting from pityriasis rubra pilaris, tinea manuum, palmar lichen planus and aquagenic palmar keratoderma), sclero-atrophic dermatoses (necrobiosis lipoidica, morphea and cutaneous lichen sclerosus), hypopigmented macular diseases (extragenital guttate lichen sclerosus, achromic pityriasis versicolor, guttate vitiligo, idiopathic guttate hypomelanosis, progressive macular hypomelanosis and postinflammatory hypopigmentations), hyperpigmented maculopapular diseases (pityriasis versicolor, lichen planus pigmentosus, Gougerot-Carteaud syndrome, Dowling-Degos disease, erythema ab igne, macular amyloidosis, lichen amyloidosus, 
friction melanosis, terra firma-forme dermatosis, urticaria pigmentosa and telangiectasia macularis eruptiva perstans), itchy papulonodular dermatoses (hypertrophic lichen planus, prurigo nodularis, nodular scabies and acquired perforating dermatosis), erythrodermas (due to psoriasis, atopic dermatitis, mycosis fungoides, pityriasis rubra pilaris and scabies), noninfectious balanitis (Zoon's plasma cell balanitis, psoriatic balanitis, seborrheic dermatitis and non-specific balanitis) and erythroplasia of Queyrat, inflammatory cicatricial alopecias (scalp discoid lupus erythematosus, lichen planopilaris, frontal fibrosing alopecia and folliculitis decalvans), nonscarring alopecias (alopecia areata, trichotillomania, androgenetic alopecia and telogen effluvium) and scaling disorders of the scalp (tinea capitis, scalp psoriasis, seborrheic dermatitis and pityriasis amiantacea).

Keywords: Dermatitis;

Dermoscopy; Differential diagnosis; Inflammoscopy; Trichoscopy

\section{INTRODUCTION}

Over the last few years, several studies have shown that dermoscopy may come in very handy for assisting the noninvasive diagnosis of various general dermatological disorders [1-6], including scalp/hair diseases (trichoscopy) [7], nail/nailfold abnormalities (onychoscopy) [8], cutaneous infections/ infestations (entomodermoscopy) [5] and inflammatory dermatoses (inflammoscopy) [1]. Indeed, such a technique provides additional information at a submacroscopic level that may help the dermatologist differentiate between two or more conditions that are hardly distinguishable with the naked eye [1]. The most important criteria to be considered when using dermoscopy in general dermatology are: (1) the morphology/arrangement of vascular structures, (2) scaling patterns, (3) colours, (4) follicular abnormalities and (5) specific features (clues) $[1,2]$. Obviously, dermoscopic findings must be interpreted within the overall clinical context of the patient (personal/family history, number, location, morphology and distribution of the lesions, etc.) because only the combination between such data can really enhance the diagnostic accuracy in the field of general dermatological disorders [1-6]. In fact, even though it has been demonstrated that some skin diseases may display "specific" dermoscopic criteria, there are others featuring just "nonspecific" findings, which may be considered useful only if coupled with proper and accurate clinical and anamnestic information [1-6]. Another crucial factor that must be taken into account in dermoscopic examination of most dermatoses is the choice of the equipment [1-6]. In particular, polarised light noncontact dermoscopy is usually preferred over conventional nonpolarised light contact dermoscopy as the latter may reduce the vessels (due to pressure) and/or scaling (when using a liquid interface) visibility, even though some clues are better seen with non-polarised light devices (i.e. more superficial findings, such as comedo-like structures) [1, 3].

The purpose of this article is to provide an up-to-date practical overview on the use of dermoscopy in general dermatology by analysing the dermoscopic differential diagnosis of several groups of relatively common dermatological disorders sharing the same (or similar) clinical presentation (erythematous-desquamative dermatoses, papulosquamous/papulokeratotic dermatoses, etc.) according to the available literature data 
and our personal experience. All published information about the dermoscopy of the conditions considered in the present article was retrieved by a comprehensive search of the literature using the PubMed electronic database (including all publications describing at least one instance); the search terms were the names of the diseases and the words "epiluminescence microscopy", "dermatoscopy" and "dermoscopy". A manual search was also carried out by analysing the reference sections of all relevant studies or reviews about such a topic.

For each clinical category, we will first describe the diseases for which there is good evidence (if any) and afterwards mention those having weaker evidence, specifying the highest level of evidence available for each considered dermatosis, according to the most recent guidelines for evidence-based medicine, The Oxford 2011 Levels of Evidence: [9] level of evidence I, systematic review of cross sectional studies with consistently applied reference standard and blinding; II, individual cross sectional studies with consistently applied reference standard and blinding; III, non-consecutive studies or studies without consistently applied reference standards; IV, case-control studies or "poor or non-independent reference standard"; V, mechanism-based reasoning. All the retrieved studies were classified according to standard definitions for diagnostic accuracy studies [10-12]. Importantly, blinded cross-sectional studies not mentioning the sampling method (consecutive or non-consecutive) were considered as non-consecutive studies (level of evidence III), while case series studies (CSS), single case reports (SCR) and personal observations (PO) were labelled as level of evidence $\mathrm{V}$. To be more accurate, we will also specify the information source type (CSS, SCR and/or PO) in case the level $\mathrm{V}$ turns out to be the best evidence available.
Tables 1, 2, 3, 4, 5 and 6 provide a summary of the dermoscopic clues of all the dermatological disorders considered, divided according to their clinical pattern.

The article is based on previously conducted studies and does not contain any new studies with human or animal subjects performed by any of the authors.

\section{DERMATOSES PRESENTING WITH ERYTHEMATOUS- DESQUAMATIVE PATCHES/ PLAQUES}

\section{Plaque Psoriasis (Level of Evidence: II)}

Dermoscopy of plaque psoriasis typically shows a characteristic pattern consisting of diffuse white scales and symmetrically and regularly distributed dotted vessels on a light or dull red background (Fig. 1a) [13-24]. When the presence of marked hyperkeratosis impedes the view of underlying features, scale removal may be useful to display the above-mentioned vascular pattern as well as possible tiny red blood drops (dermoscopic "Auspitz sign") [21]. The "red globular ring" pattern is another less common (but specific) vascular pattern visible in plaque psoriasis lesions, while other patterns of vessel distribution are extremely rare [25].

\section{Eczematous Dermatitis (Level of Evidence:}

II)

The most important dermoscopic features of eczematous dermatitis include dotted vessels in a patchy distribution and yellow serocrusts/ scaling (Fig. 1b) [13, 26-28]. Focal whitish scales are sometimes visible, but they are always associated with the aforementioned "yellowish findings" [13, 26-28]. According to the disease stage, eczematous dermatitis may display some 


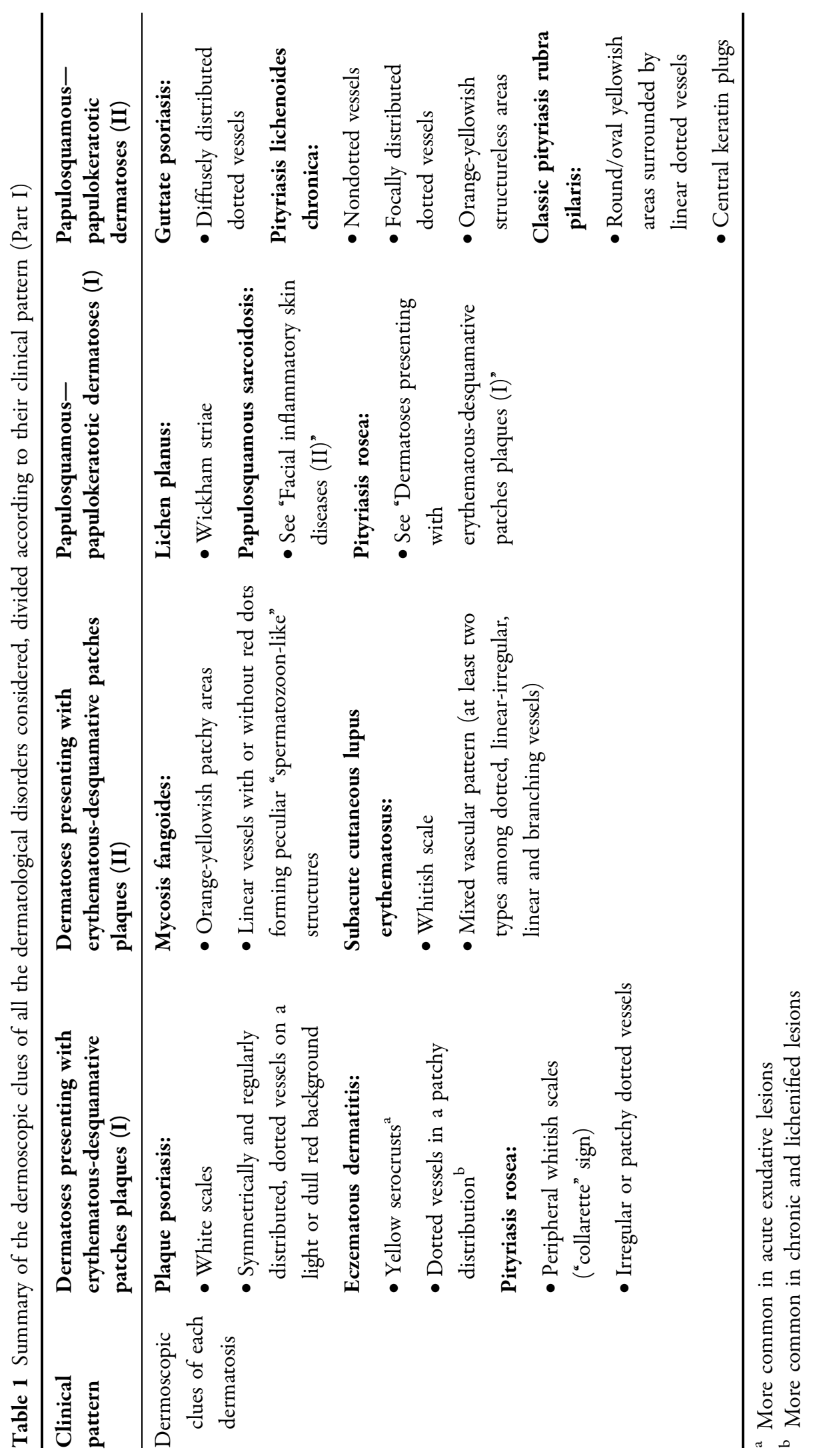


Table 2 Summary of the dermoscopic clues of all the dermatological disorders considered, divided according to their clinical pattern (Part II)

\begin{tabular}{|c|c|c|c|c|}
\hline $\begin{array}{l}\text { Clinical } \\
\text { pattern }\end{array}$ & $\begin{array}{l}\text { Papulosquamous- } \\
\text { papulokeratotic dermatoses } \\
\text { (III) }\end{array}$ & $\begin{array}{l}\text { Papulosquamous- } \\
\text { papulokeratotic dermatoses } \\
\text { (IV) }\end{array}$ & $\begin{array}{l}\text { Facial } \\
\text { inflammatory } \\
\text { skin diseases }(I)\end{array}$ & $\begin{array}{l}\text { Facial } \\
\text { inflammatory } \\
\text { skin diseases (II) }\end{array}$ \\
\hline $\begin{array}{l}\text { Dermoscopic } \\
\text { clues of } \\
\text { each } \\
\text { dermatosis }\end{array}$ & $\begin{array}{l}\text { Disseminated forms of } \\
\text { porokeratosis: } \\
\text { - Peripheral "cornoid } \\
\text { lamella" } \\
\text { Lymphomatoid papulosis: } \\
\text { - Diffuse tortuous irregular (or } \\
\text { dotted at low magnification) } \\
\text { vessels (early lesions) } \\
\text { - Central whitish-yellowish } \\
\text { (hyperkeratotic lesions) or } \\
\text { brown-grey (necrotic lesions) } \\
\text { structureless area } \\
\text { Papulosquamous chronic } \\
\text { GVHD: } \\
\text { - Whitish scales } \\
\text { - Dotted and linear vessels }\end{array}$ & $\begin{array}{l}\text { Poikiloderma vasculare } \\
\text { atrophicans: } \\
\text { - Sparse whitish scales } \\
\text { - Blurred branched vessels on a } \\
\text { reddish/orangish background } \\
\text { Grover disease, Darier disease } \\
\text { and BRAF-inhibitor- } \\
\text { induced acantholytic } \\
\text { dyskeratosis: } \\
\text { - Central star-shaped/branched } \\
\text { polygonal/roundish-oval } \\
\text { brownish area surrounded by } \\
\text { a whitish halo }\end{array}$ & $\begin{array}{l}\text { Rosacea: } \\
\text { - Linear vessels } \\
\text { arranged in a } \\
\text { polygonal } \\
\text { network } \\
\text { Seborrheic } \\
\text { dermatitis: } \\
\text { - Dotted vessels } \\
\text { in a patchy } \\
\text { distribution } \\
\text { - Fine yellowish } \\
\text { scales } \\
\text { Discoid lupus } \\
\text { erythematosus: } \\
\text { - Perifollicular } \\
\text { whitish halo } \\
\text { (early lesions) } \\
\text { - Follicular } \\
\text { keratotic plugs, } \\
\text { red dots (early } \\
\text { lesions) } \\
\text { - White scaling } \\
\text { (early lesions) } \\
\text { - Whitish } \\
\text { structureless } \\
\text { areas (late } \\
\text { lesions) } \\
\text { - Blurred linear } \\
\text { branching (late } \\
\text { lesions) }\end{array}$ & $\begin{array}{l}\text { Sarcoidosis, } \\
\text { cutaneous } \\
\text { leishmaniasis } \\
\text { and lupus } \\
\text { vulgaris: } \\
\text { - Diffuse or } \\
\text { localised, } \\
\text { structureless, } \\
\text { orange yellowish } \\
\text { areas } \\
\text { - Focussed linear } \\
\text { or branching } \\
\text { vessels } \\
\text { Granuloma } \\
\text { faciale: } \\
\text { - Dilated follicular } \\
\text { openings } \\
\text { - Linear branching } \\
\text { vessels } \\
\text { Demodicidosis: } \\
\text { - "Demodex tails" } \\
\text { - “Demodex } \\
\text { follicular } \\
\text { openings" }\end{array}$ \\
\hline
\end{tabular}

${ }^{a}$ Grover disease (spongiotic variant) may also display whitish scaling over a reddish-yellowish background

b "Demodex follicular openings" appear as round and coarse follicular openings containing light brown/greyish plugs surrounded by an erythematous halo, while "demodex follicular openings" appear as round and coarse follicular openings containing light brown/greyish plugs surrounded by an erythematous halo 
Table 3 Summary of the dermoscopic clues of all the dermatological disorders considered, divided according to their clinical pattern (Part III)

\begin{tabular}{|c|c|c|c|c|}
\hline $\begin{array}{l}\text { Clinical } \\
\text { pattern }\end{array}$ & $\begin{array}{l}\text { Acquired } \\
\text { keratodermas (I) }\end{array}$ & $\begin{array}{l}\text { Acquired } \\
\text { keratodermas (II) }\end{array}$ & Sclero-atrophic dermatoses & $\begin{array}{l}\text { Hypopigmented } \\
\text { macular diseases } \\
\text { (I) }\end{array}$ \\
\hline $\begin{array}{l}\text { Dermoscopic } \\
\text { clues of } \\
\text { each } \\
\text { dermatosis }\end{array}$ & $\begin{array}{l}\text { Palmar psoriasis: } \\
\text { - Diffuse white } \\
\text { scaling } \\
\text { Chronic hand } \\
\text { eczema: } \\
\text { - Brownish-orange } \\
\text { dots/globules } \\
\text { - Yellowish scales/ } \\
\text { crusts } \\
\text { Keratoderma due } \\
\text { to mycosis } \\
\text { fungoides: } \\
\text { - Relatively large, } \\
\text { amber scales over a } \\
\text { white-to-pinkish } \\
\text { background } \\
\text { Keratoderma due } \\
\text { to pityriasis rubra } \\
\text { pilaris: } \\
\text { - Patchily } \\
\text { distributed, } \\
\text { homogeneous, } \\
\text { structureless, } \\
\text { orange areas }\end{array}$ & $\begin{array}{l}\text { Tinea manuum: } \\
\text { - Whitish scales } \\
\text { mainly localised in } \\
\text { the creases } \\
\text { Palmar lichen } \\
\text { planus: } \\
\text { - Roundish, } \\
\text { yellowish } \\
\text { areas often having } \\
\text { peripheral } \\
\text { projections } \\
\text { Aquagenic palmar } \\
\text { keratoderma: } \\
\text { - Yellowish-whitish } \\
\text { well-defined } \\
\text { globules } \\
\text { - Enlargement of } \\
\text { the sweat duct } \\
\text { pores }\end{array}$ & $\begin{array}{l}\text { Morphea: } \\
\text { - Fibrotic beams } \\
\text { Lichen sclerosus: } \\
\text { - "Comedo-like openings" } \\
\text { - Whitish patches } \\
\text { Necrobiosis lipoidica: } \\
\text { - Yellowish-orange/whitish-pinkish } \\
\text { background } \\
\text { - Comma-shaped (incipient lesions), } \\
\text { network-shaped/hairpin-like (more } \\
\text { developed lesions), or elongated, } \\
\text { branching and focussed serpentine } \\
\text { (advanced lesions) vessels }\end{array}$ & $\begin{array}{l}\text { Extragenital } \\
\text { guttate lichen } \\
\text { sclerosus: } \\
\text { - See } \\
\text { "Sclero-atrophic } \\
\text { dermatoses" } \\
\text { Achromic pityriasis } \\
\text { versicolor: } \\
\text { - Fairly demarcated } \\
\text { white area. Fine } \\
\text { scales in the skin } \\
\text { furrows } \\
\text { Guttate vitiligo: } \\
\text { - Well-demarcated, } \\
\text { dense/glowing, } \\
\text { white area } \\
\text { - Perifollicular } \\
\text { hyperpigmentation }\end{array}$ \\
\hline
\end{tabular}

differences, with acute exudative lesions mainly showing yellow scale/crusts ("yellow clod sign") and chronic and lichenified lesions predominantly displaying dotted vessels in a patchy distribution and scaling $[1,13,29,30]$.

\section{Pityriasis Rosea (Level of Evidence: II)}

Both the herald patch and the secondary lesions of pityriasis rosea typically show a characteristic peripheral whitish scaling ("collarette" sign) as well as dotted vessels, which, differently from psoriasis, are distributed in an irregular or focal pattern; diffuse or localised yellowish-orange structureless areas may be visible as well (Fig. 1c) [13, 31, 32].

\section{Mycosis Fungoides (Level of Evidence: III)}

The most common dermoscopic aspect of mycosis fungoides consists of a combination of fine short linear vessels with 
Table 4 Summary of the demioscopic clues of all the dermatological disorders considered, divided according to their clinical pattern (Part IV)

\begin{tabular}{|c|c|c|c|c|}
\hline $\begin{array}{l}\text { Clinical } \\
\text { pattern }\end{array}$ & $\begin{array}{l}\text { Hypopigmented } \\
\text { macular diseases (II) }\end{array}$ & $\begin{array}{l}\text { Hyperpigmented } \\
\text { maculopapular diseases } \\
\text { (I) }\end{array}$ & $\begin{array}{l}\text { Hyperpigmented } \\
\text { maculopapular diseases (II) }\end{array}$ & $\begin{array}{l}\text { Hyperpigmented } \\
\text { maculopapular } \\
\text { diseases (III) }\end{array}$ \\
\hline $\begin{array}{l}\text { Dermoscopic } \\
\text { clues of } \\
\text { each } \\
\text { dermatosis }\end{array}$ & $\begin{array}{l}\text { Idiopathic guttate } \\
\text { hypomelanosis: } \\
\text { - "Cloudy sky-like" or } \\
\text { "cloudy" pattern" } \\
\text { Progressive macular } \\
\text { hypomelanosis: } \\
\text { - Ill-defined whitish } \\
\text { area without scaling } \\
\text { Postinflammatory } \\
\text { hypopigmentation: } \\
\text { - Dermoscopic } \\
\text { findings typical of } \\
\text { the original lesions }\end{array}$ & $\begin{array}{l}\text { Pityriasis versicolor: } \\
\text { - Fine whitish scaling } \\
\text { - Pigmented network } \\
\text { composed of brown } \\
\text { stripes/diffuse brownish } \\
\text { pigmentation } \\
\text { Lichen planus } \\
\text { pigmentosus: } \\
\text { - Diffuse, structureless, } \\
\text { brownish pigmentation } \\
\text { - Fine/coarse, grey-blue/ } \\
\text { brown dots/globules } \\
\text { Confluent and } \\
\text { reticulated } \\
\text { papillomatosis } \\
\text { (Gougerot-Carteaud } \\
\text { syndrome): } \\
\text { - Fine whitish scaling } \\
\text { - Brownish areas in a } \\
\text { "cobblestone" or "sulci } \\
\text { and gyri" pattern }\end{array}$ & $\begin{array}{l}\text { Dowling-Degos disease: } \\
\text { - Brown star-like area/ } \\
\text { irregular brownish } \\
\text { projections with a } \\
\text { hypopigmented centre } \\
\text { Erythema ab igne } \\
\text { (hyperpigmented stage): } \\
\text { - Diffuse brownish } \\
\text { pigmentation } \\
\text { - Telangiectatic vessels } \\
\text { - Whitish scaling } \\
\text { Macular amyloidosis and } \\
\text { lichen amyloidosus: } \\
\text { - White or brown central hub } \\
\text { surrounded by various } \\
\text { configurations of brownish } \\
\text { pigmentation }{ }^{b}\end{array}$ & $\begin{array}{l}\text { Friction melanosis: } \\
\text { - Brownish } \\
\text { structureless areas } \\
\text { arranged in a } \\
\text { reticular fashion } \\
\text { Terra firma-forme } \\
\text { dermatosis: } \\
\text { - Large polygonal } \\
\text { plate-like brown } \\
\text { scales arranged in a } \\
\text { mosaic pattern } \\
\text { Urticaria } \\
\text { pigmentosa: } \\
\text { - Homogeneous } \\
\text { light-brown blot } \\
\text { and/or pigment } \\
\text { network } \\
\text { Telangiectasia } \\
\text { macularis eruptiva } \\
\text { perstans: } \\
\text { - Reticular vessels on } \\
\text { a erythematous or } \\
\text { brownish base }\end{array}$ \\
\hline
\end{tabular}

${ }^{a}$ The "cloudy sky-like" pattern consists of multiple small areas coalescing into irregular/porycyclic macules, with several white shades and both well- and ill-defined edges, surrounded by patchy hyperpigmented network, while the "cloudy" pattern consists of well or ill-defined roundish homogeneous whitish areas surrounded by patchy hyperpigmented network ${ }^{b}$ In lichen amyloidosus the central hub may be replaced by a scar-like area

orange-yellowish patchy areas (Fig. 1d) [33]; a peculiar vascular structure resembling spermatozoa (composed of a dotted and a short curved linear vessel) is also quite frequently visible [33]. Additional dermoscopic features are represented by fine white scaling, dotted vessels and purpuric dots [33].

\section{Subacute Cutaneous Lupus erythematosus (Level of Evidence: V-CSS)}

Subacute cutaneous lupus erythematosus is characterised by two constant dermoscopic findings, namely whitish scales (diffusely or 
Table 5 Summary of The dermoscopic clues of all the dermatological disorders considered, divided according to their clinical pattern (Part V)

\begin{tabular}{|c|c|c|c|c|}
\hline $\begin{array}{l}\text { Clinical } \\
\text { pattern }\end{array}$ & $\begin{array}{l}\text { Itchy } \\
\text { papulonodular } \\
\text { dermatoses }\end{array}$ & Erythrodermas (I) & Erythrodermas (II) & $\begin{array}{l}\text { Noninfectious } \\
\text { balanitis-erythroplasia } \\
\text { of Queyrat }\end{array}$ \\
\hline $\begin{array}{l}\text { Dermoscopic } \\
\text { clues of } \\
\text { each } \\
\text { dermatosis }\end{array}$ & $\begin{array}{l}\text { Hypertrophic } \\
\text { lichen planus: } \\
\text { - Rippled surface } \\
\text { - "Comedo-like” } \\
\text { structures } \\
\text { - Round corneal } \\
\text { structures } \\
\text { (“corn pearls”) } \\
\text { Prurigo } \\
\text { nodularis: } \\
\text { - "White } \\
\text { starburst” } \\
\text { pattern" } \\
\text { Nodular } \\
\text { scabies: } \\
\text { - Mites (“hang } \\
\text { glider sign”) } \\
\text { - Burrows (“jet } \\
\text { with } \\
\text { condensation } \\
\text { trails”) } \\
\text { Acquired } \\
\text { perforating } \\
\text { dermatosis: } \\
\text { - Three } \\
\text { concentric } \\
\text { areas with } \\
\text { different } \\
\text { aspect/colour }\end{array}$ & $\begin{array}{l}\text { Erythrodermic } \\
\text { psoriasis: } \\
\text { - Diffusely } \\
\text { distributed whitish } \\
\text { scales } \\
\text { - Regularly arranged } \\
\text { dotted/glomerular } \\
\text { vessels } \\
\text { Erythrodermic } \\
\text { atopic dermatitis: } \\
\text { - Yellowish scales/ } \\
\text { sero crusts } \\
\text { - Patchily distributed } \\
\text { dotted vessels } \\
\text { Erythrodermic } \\
\text { mycosis fungoides: } \\
\text { - Linear vessels } \\
\text { (including } \\
\text { spermatozoon-like } \\
\text { vessels) and dotted } \\
\text { vessels }\end{array}$ & $\begin{array}{l}\text { Erythrodermic pityriasis rubra } \\
\text { pilaris: } \\
\text { - Orange blotches } \\
\text { - Islands of nonerythematous } \\
\text { (spared) skin displaying reticular } \\
\text { vessels } \\
\text { Erythrodermic scabies: } \\
\text { - Dark-brown triangular structures } \\
\text { located at the end of whitish } \\
\text { structureless wavy lines } \\
\text { (delta-wing jets with contrail) }\end{array}$ & $\begin{array}{l}\text { Zoon's plasma cell } \\
\text { balanitis: } \\
\text { - Focal/diffuse } \\
\text { orange-yellowish } \\
\text { structureless areas } \\
\text { - Fairly focussed curved } \\
\text { vessels (including } \\
\text { serpentine, convoluted } \\
\text { and chalice-shaped) } \\
\text { Psoriatic balanitis: } \\
\text { - Regularly distributed } \\
\text { dotted/glomerular } \\
\text { vessels } \\
\text { Seborrheic dermatitis } \\
\text { and non-specific } \\
\text { balanitis: } \\
\text { - Linear irregular } \\
\text { unspecific blurry vessels } \\
\text { Erythroplasia of } \\
\text { Queyrat: } \\
\text { - Scattered glomerular } \\
\text { vessels }\end{array}$ \\
\hline
\end{tabular}

a Consists of radially arranged whitish lines or a peripheral whitish halo with some centrifugal coarse projections on a brownish and/or reddish background, which may surround brown-reddish/brown-yellowish crust(s), erosion(s) and/or hyperkeratosis/scales

peripherally distributed) and a mixed vascular pattern (at least two types of vessels among dotted, linear-irregular, linear and branching vessels) over a pinkish-reddish background [34]. Focally distributed orange-yellowish structureless areas may also be seen less commonly [34]. 


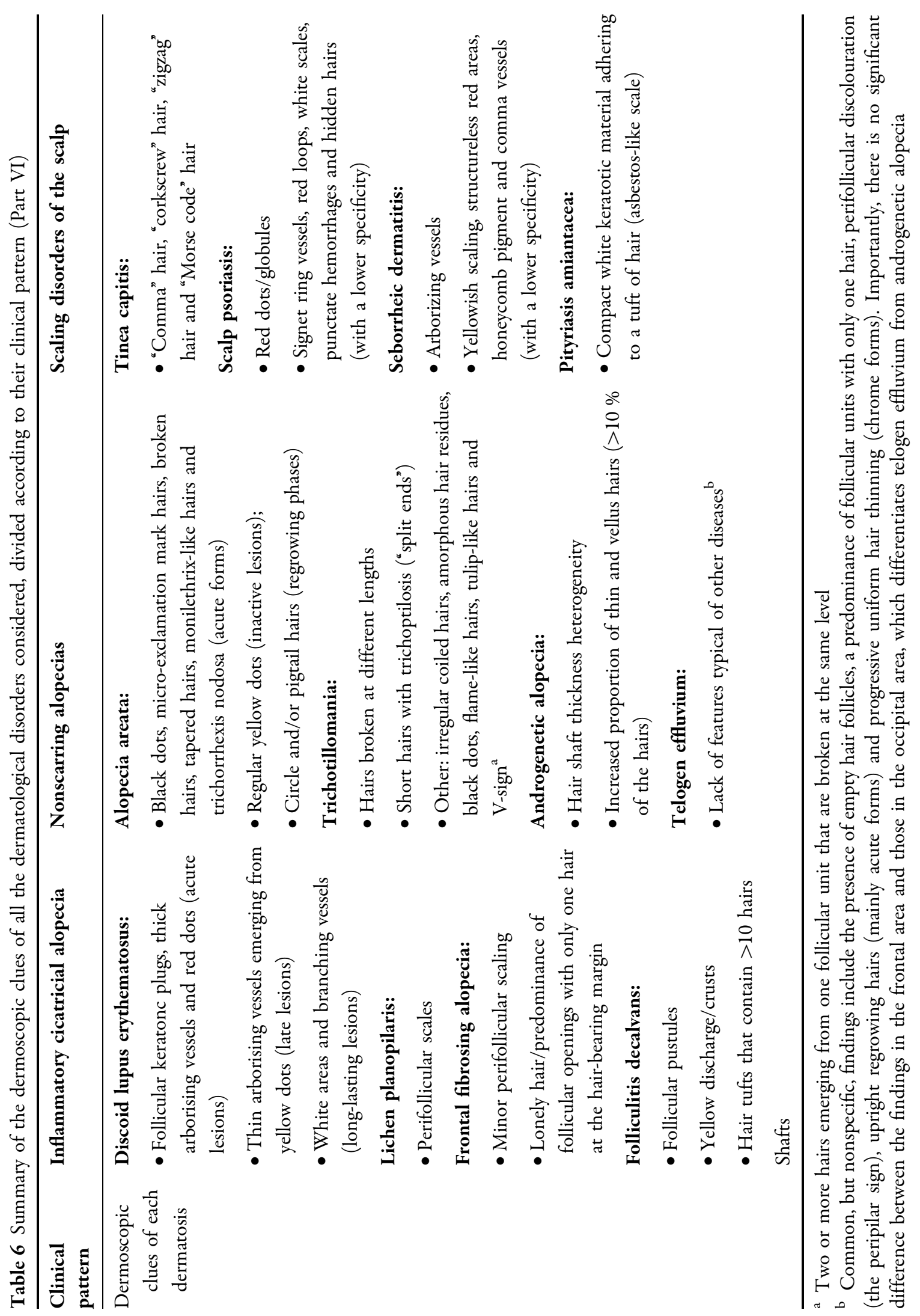



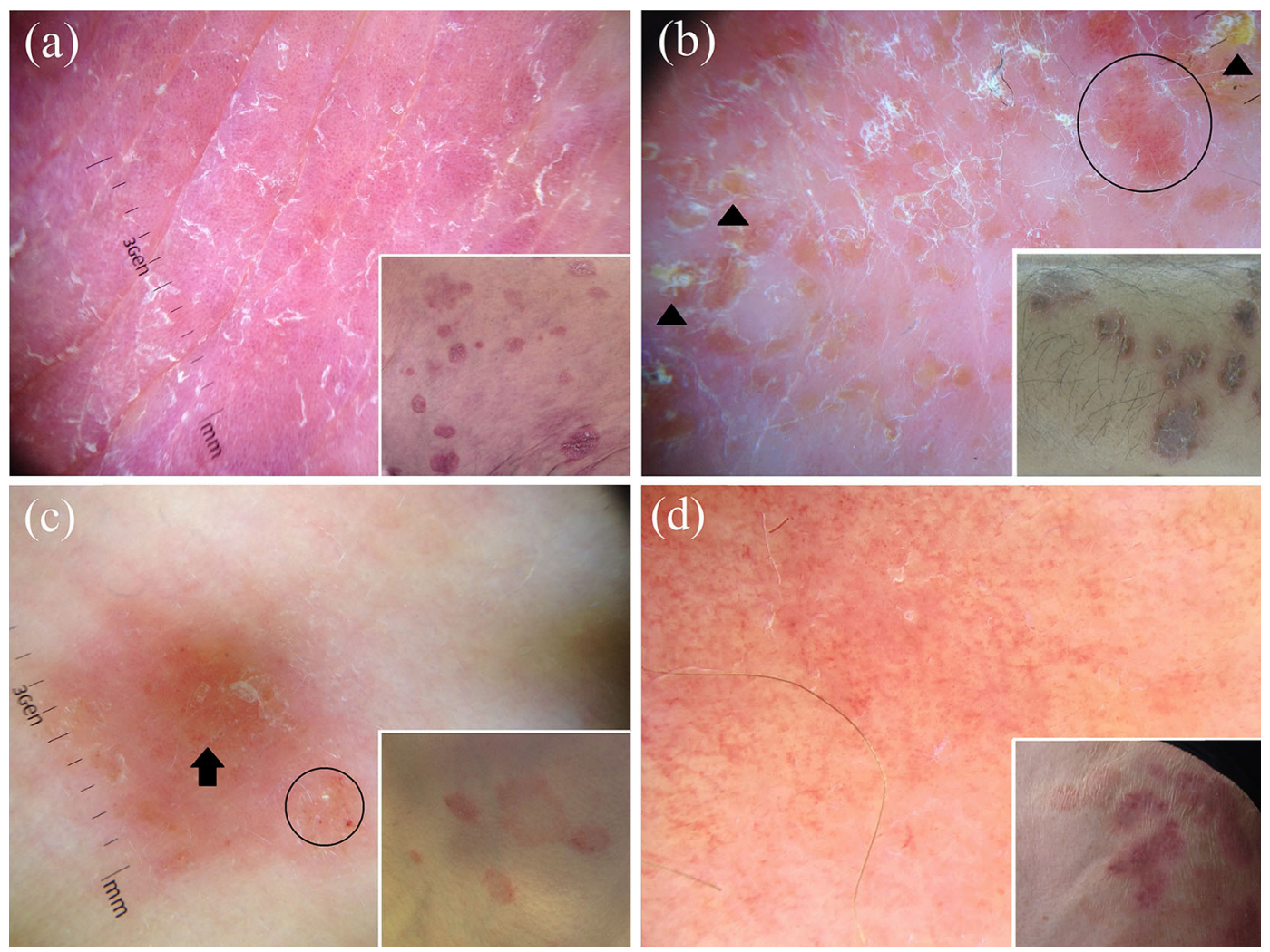

Fig. 1 Dermoscopy of plaque psoriasis typically shows white scales and symmetrically and regularly distributed dotted vessels on a red background (a). The main dermoscopic criteria in eczematous dermatitis are dotted vessels (black circle) in a patchy distribution and yellow serocrusts (black arrowhead) (b). Both the herald patch and the secondary lesions of pityriasis rosea are

\section{PAPULOSQUAMOUS/ PAPULOKERATOTIC DERMATOSES}

\section{Classical Lichen Planus (Level of Evidence: II)}

The dermoscopic hallmark of classical lichen planus is represented by Wickham striae (Fig. 2a), which may appear as pearly-whitish (and less commonly yellow or blue-white) structures possibly displaying several morphological patterns, including reticular (the most common), linear, "radial streaming", annular, round, "leaf venation"

dermoscopically characterised by peculiar peripheral whitish scales ("collarette" sign) as well as irregular or patchy dotted vessels (black circle); structureless orangish areas are also visible (black arrow) (c). Dermoscopic examination of mycosis fungoides reveals a combination of fine short, linear vessels with orange-yellowish patchy areas (d)

(delicate secondary striae branching from the centred whitish venation, linked together at either end, mimicking the crystal structure of snow) and "starry sky" (clustered, follicular white dots) aspect [13-15, 35-39]. Dotted, globular and/or linear vessels, mainly localised at the periphery of the lesion (and less commonly showing a perifollicular or diffuse pattern), violet, reddish, pink, brown or yellow background, white/yellow dots and some pigmented structures (dots, globules and/ or reticular or cloud-like areas) are other additional dermoscopic findings of active lesions [13-15, 35-39]. 

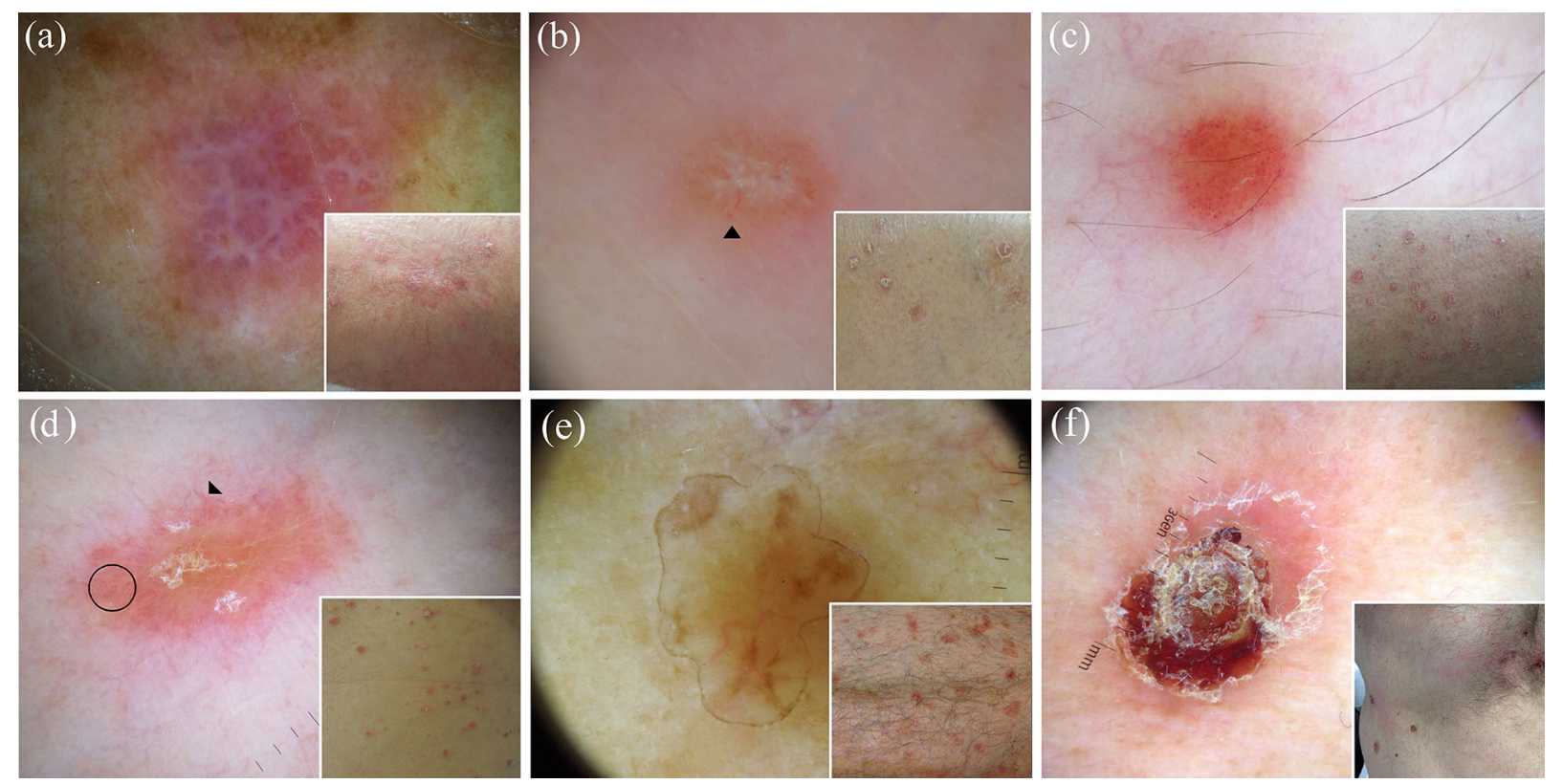

Fig. 2 The dermoscopic analysis of classical lichen planus typically shows the Wickham striae over a purplish background (a). Dermoscopy of papulosquamous sarcoidosis shows the characteristic orange-yellowish background, in combination with in-focus fine linear vessels (black arrowhead); whitish lines and white scales are also evident in the centre (b). Guttate psoriasis lesions typically show a distinctive monomorphic dermoscopic picture, with dotted vessels distributed in a diffuse pattern $(\mathbf{c})$. Dermoscopy of

\section{Pityriasis Rosea (Level of Evidence: II)}

See the section "Dermatoses presenting with erythematous-desquamative patches/plaques".

\section{Papulosquamous Sarcoidosis (Level of Evidence: II)}

See the section "Common facial inflammatory skin diseases" (Fig. 2b).

\section{Guttate Psoriasis (Level of Evidence: III)}

Guttate psoriasis classically displays a distinctive monomorphic dermoscopic aspect consisting of dotted vessels regularly distributed pityriasis lichenoides chronica frequently displays nondotted vessels, e.g. linear irregular vessels (black arrowhead), focally distributed dotted vessels (black circle) and orange-yellowish structureless areas (d). Dermoscopic examination of a case of disseminated superficial actinic porokeratosis displays the peculiar "cornoid lamella" at the periphery of the lesion (e). Dermoscopy of a necrotic lesion of lymphomatoid papulosis shows a central brown-grey structureless area (f)

all over the lesion, which are often associated with whitish scales (Fig. 2c) [1, 40], similarly to that seen in plaque-type psoriasis [1-6, 41]; orange-yellowish structureless areas may also be present, but they are quite uncommon [40].

\section{Pityriasis Lichenoides Chronica (Level of Evidence: III)}

The most peculiar dermoscopic findings of pityriasis lichenoides chronica include nondotted vessels (i.e. milky red areas/globules, linear irregular and branching vessels), focally distributed dotted vessels and orange-yellowish structureless areas (Fig. 2d) [40]. Interestingly, whitish areas may 
sometimes be present in the context of clinically active lesions as a result of focal post-inflammatory hypopigmentation $[1,40]$.

\section{Classical Pityriasis Rubra Pilaris (Level of Evidence: V-CSS, CR)}

Dermoscopy of classical pityriasis rubra pilaris papules may show round/oval yellowish areas surrounded by vessels of mixed morphology, namely linear and dotted [1, 16]. Additionally, central keratin plugs may also be observed [1].

\section{Disseminated Forms of Porokeratosis (Level of Evidence: V-CSS, CR)}

The most peculiar dermoscopic feature of all variants of porokeratosis is the "cornoid lamella", which appears as a well-defined, thin, white-yellowish, annular peripheral hyperkeratotic structure ("white track") similar to the outlines of a volcanic crater as observed from a high point, which may be hyperpigmented in disseminated superficial actinic porokeratosis (Fig. 2e); the centre of the lesions is usually whitish or brownish and may exhibit circular and/or linear whitish and/or hyperpigmented tracks, blue-grey dots and dotted, linear or globular vessels (Fig. 2e) $[17,42-49]$.

\section{Lymphomatoid Papulosis (Level of Evidence: V-CSS)}

Dermoscopic pattern of lymphomatoid papulosis varies according to the disease stage. The initial inflammatory papules usually display a vascular pattern of tortuous irregular (or dotted at low magnification) vessels, surrounded by white structureless areas, radiating from the centre to the periphery of the lesion, while in more mature papules, such a vascular pattern is less evident and generally detectable only at the periphery of the lesion as the centre is occupied by a whitish-yellowish (hyperkeratotic lesions) or brown-grey (necrotic lesions) structureless area (Fig. 2f) [50].

\section{Papulosquamous Chronic GVHD (Level of Evidence: V-CSS)}

The dermoscopic aspect of papulosquamous chronic GVHD consists of whitish scales associated with vessels of mixed morphology, namely dotted and linear [1]. Although such a pattern is quite unspecific, it might be useful in assisting the clinical differential diagnosis with the other above-mentioned papulosquamous disorders as they typically show a different appearance [1].

\section{Poikiloderma Vasculare Atrophicans/ Parakeratosis Variegata (Level of Evidence: V-CSS)}

This condition typically shows a monomorphic pattern consisting of relatively blurred branched vessels on a reddish or orangish-brown background, associated with sparse whitish scales [51].

Acantholytic and Dyskeratotic Papular Disorders (Grover Disease, Darier Disease and BRAF-Inhibitor-Induced Acantholytic Dyskeratosis; Level of Evidence: V-CSS, CR)

Grover disease may display different features according to the histological subtype, with a central star-shaped/branched polygonal/ roundish-oval brownish area surrounded by a 


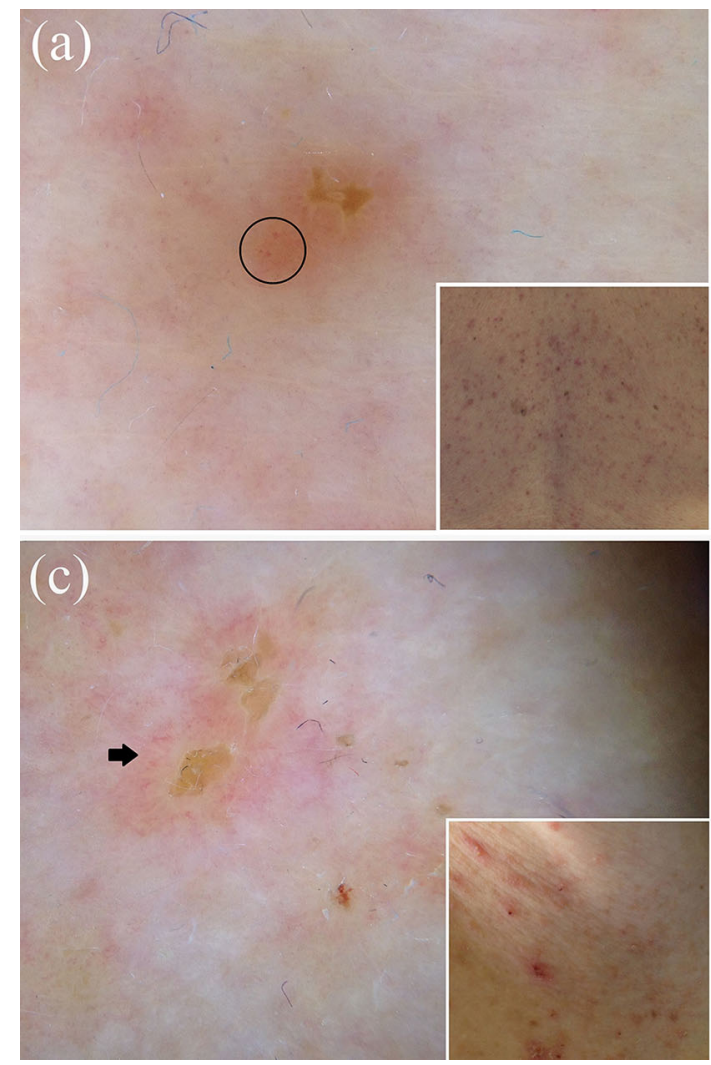

Fig. 3 Dermoscopy of Darier-like Grover disease displays a central branched polygonal brownish area surrounded by a thin whitish halo with peripheral dotted vessels (black circle) (a), while spongiotic Grover disease presents with whitish scaling over a reddish-yellowish background and irregular vessels (black circle) (b). Dermoscopic examination of Darier disease (c) and BRAF-inhibitor-induced

whitish halo being characteristic of the Darier-like histological subtype (Fig. 3a) and whitish scaling over a reddish-yellowish background being characteristic of the spongiotic histological subtype (Fig. 3b); dotted and/or linear/irregular vessels may be found in both such forms (Fig. 3a, b) [52-55]. Importantly, the dermoscopic pattern of Darier-like Grover disease overlaps with that detectable in both Darier disease and BRAF-inhibitor-induced acantholytic dyskeratosis (Fig. 3c, d) [55-58].

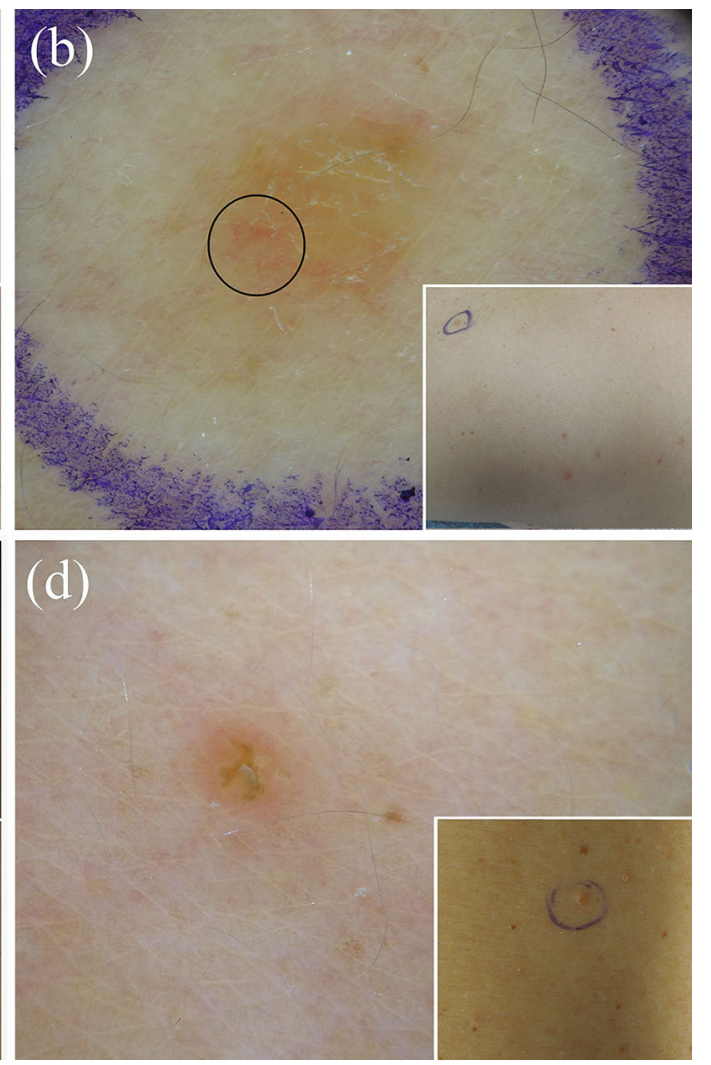

acantholytic dyskeratosis (d) shows a pattern similar to that observed in Darier-like Grover disease, with a centrally located polygonal brownish area surrounded by a whitish halo and linear vessels (black arrow) in Darier disease (c) and a central branched polygonal brownish area surrounded by a thin whitish halo in the latter condition (d)

\section{COMMON FACIAL INFLAMMATORY SKIN DISEASES}

\section{Rosacea (Level of Evidence: III)}

The dermoscopic hallmark of rosacea is represented by the presence of linear vessels characteristically arranged in a polygonal network (vascular polygons) [26, 59] (Fig. 4a). Additional features include rosettes [60], follicular plugs, white/yellowish scales, orange-yellowish areas, pigmentation 

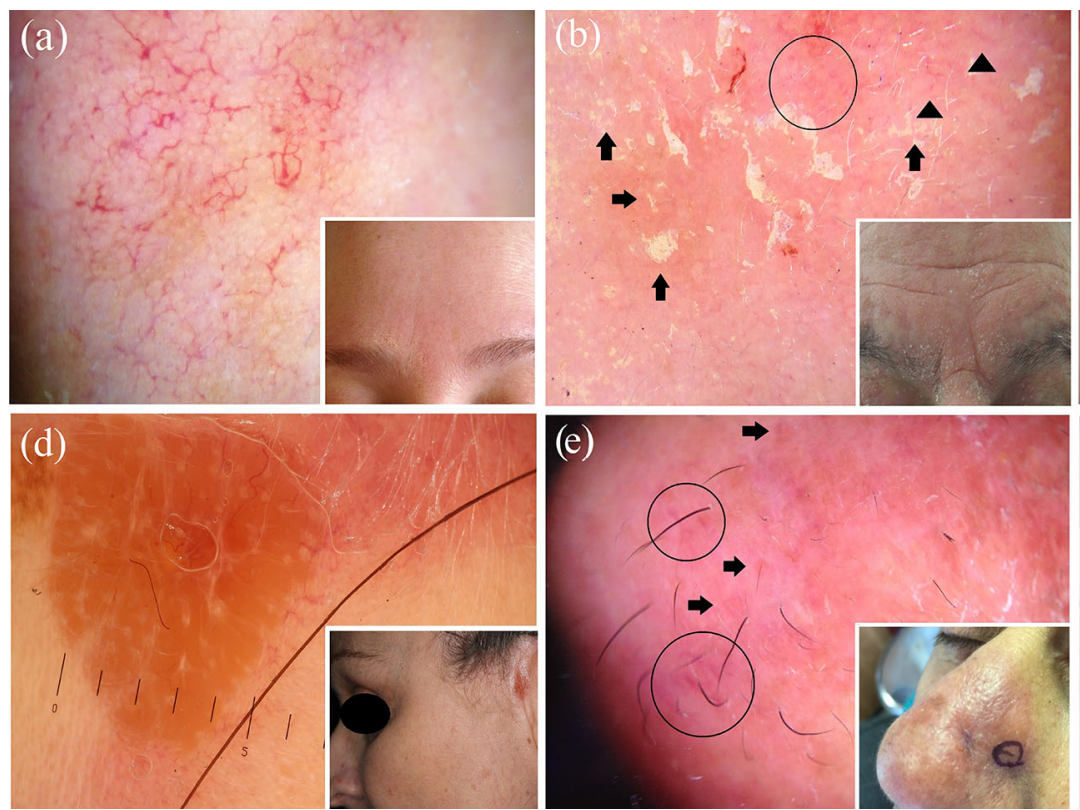
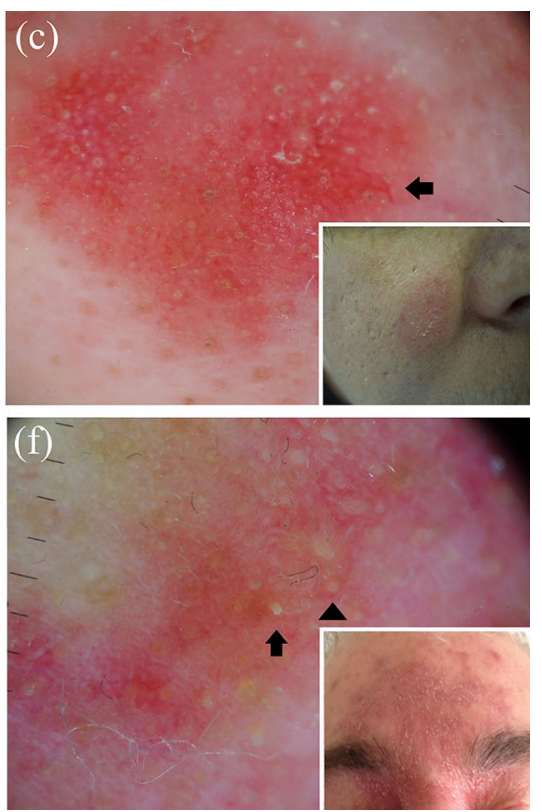

Fig. 4 The main dermoscopic feature of rosacea is the presence of linear vessels, which are characteristically arranged in a polygonal network (a). The most typical dermoscopic finding of seborrheic dermatitis is represented by the presence of dotted vessels in a patchy distribution (black circle) and yellowish scales (black arrows); blurry linear branching vessels (black arrowheads) and whitish scales are also not uncommonly present (b). Dermoscopy of an intermediate-stage lesion of facial discoid lupus erythematosus reveals follicular white/yellowish rings/ keratotic plugs, whitish scaling and blurred branching vessels (black arrow) over a reddish background (c).

structures, dilated follicles and follicular pustules (papulopustular rosacea) $[26,59]$.

\section{Seborrheic Dermatitis (Level of Evidence: III)}

The most typical dermoscopic findings of seborrheic dermatitis include dotted vessels in a patchy distribution and fine yellowish scales (in combination or not with white scales) (Fig. 4b); follicular plugs, orange-yellowish areas, whitish structureless areas and linear branching vessels are less common features [26].
Dermoscopic examination of facial sarcoidosis displays a structureless orange-yellowish background with focussed linear vessels (d), while granuloma faciale features dilated follicular openings (black arrows) associated with linear/ branching vessels (black circles) over a pinkish background (e). Dermoscopy of demodicidosis shows the so-called "Demodex tails", which are visualised as creamy/whitish gelatinous threads protruding out of follicular openings (black arrow), and "Demodex follicular openings", which appear as round and coarse follicular openings containing light brown/greyish plugs surrounded by an erythematous halo (black arrowhead) (f)

\section{Discoid Lupus erythematosus (Level of Evidence: III)}

Dermoscopy of facial (and extra-scalp in general) discoid lupus erythematosus shows different features according to the stage of disease, with erythema, perifollicular whitish halo, follicular keratotic plugs, red dots and white scaling being the most common/characteristic features of early lesions, and whitish structureless areas, hyperpigmentation (honeycomb network, perifollicular pigmentation, radial pigment streaks or pigmentation arranged in unspecified pattern) and blurred telangiectasias (mainly 
linear branching vessels and less commonly dotted/polymorphous vessels) representing the most frequent findings of late phases [26, 61-65]; intermediate-stage lesions may display a mixture of the aforementioned features (Fig. 4c) [26, 61-65]. Less common dermoscopic findings include diffuse hyperkeratosis (hypertrophic discoid lupus erythematosus) [65], dilated follicles and yellowish scales [26, 61-65].

\section{Granulomatous Skin Diseases (Sarcoidosis, Cutaneous Leishmaniasis and Lupus Vulgaris; Level of Evidence: III)}

The dermoscopic signature of all these granulomatous facial dermatoses consists of structureless orange-yellowish areas (diffuse or localised-often described as "grains of sand" in lupus vulgaris and teardrop-like areas in leishmaniasis), commonly associated with focussed linear or branching vessels (Fig. 4d) [26, 66-80]. Other possible findings include milia-like cysts, erythema, whitish lines or structureless areas, follicular plugs, dilated follicles, pigmentation structures, and white and/or yellow scales [26, 66-80]. Additionally, leishmaniasis has been reported to show hyperkeratosis, further vascular features (hairpin, comma-shaped, glomerular-like and/ or corkscrew vessels), central ulcerations and white peripheral projections (white starburst pattern) [73-80]. Nevertheless, dermoscopy may not be considered as a reliable tool in differentiating such granulomatous diseases and therefore histological assessment is needed to reach a definitive diagnosis [26, 66-80].

\section{Granuloma Faciale (Level of Evidence: III)}

The dermoscopic hallmark of granuloma faciale is represented by the presence of dilated follicular openings associated with linear branching vessels (which sometimes appear as focussed elongated telangiectasias) over a pinkish background (Fig. 4e) [26, 81-83]; additional findings include perifollicular whitish halo, whitish streaks, follicular plugs, yellowish scales and pigmentation structures [26, 81-83].

\section{Demodicidosis (Level of Evidence: V—CSS)}

The most indicative dermoscopic features of all types of demodicidosis are the so-called "Demodex tails", which are creamy/whitish gelatinous threads (representing the presence of the mite itself under magnification) protruding out of follicular openings, and "Demodex follicular openings", which appear as round and coarse follicular openings containing light brown/greyish plugs surrounded by an erythematous halo (Fig. 4f) [84]. Other unspecific dermoscopic findings (whose prevalence varies according to the subtypes of demodicidosis) include diffuse erythema, scaling, pustules and reticular dilated vessels [84].

\section{ACQUIRED KERATODERMAS}

\section{Chronic Hand Eczema (Level of Evidence: III)}

The most specific dermoscopic features of chronic hand eczema include brownish-orange dots/globules (corresponding to tiny spongiotic vesicles), yellowish scales and yellowish-orange crusts $[28,85]$; other less common findings are focally distributed whitish scaling and dotted vessels (Fig. 5a) [28, 85].

\section{Palmar Psoriasis (Level of Evidence: III)}

The main dermoscopic finding of palmar psoriasis is represented by the presence of 

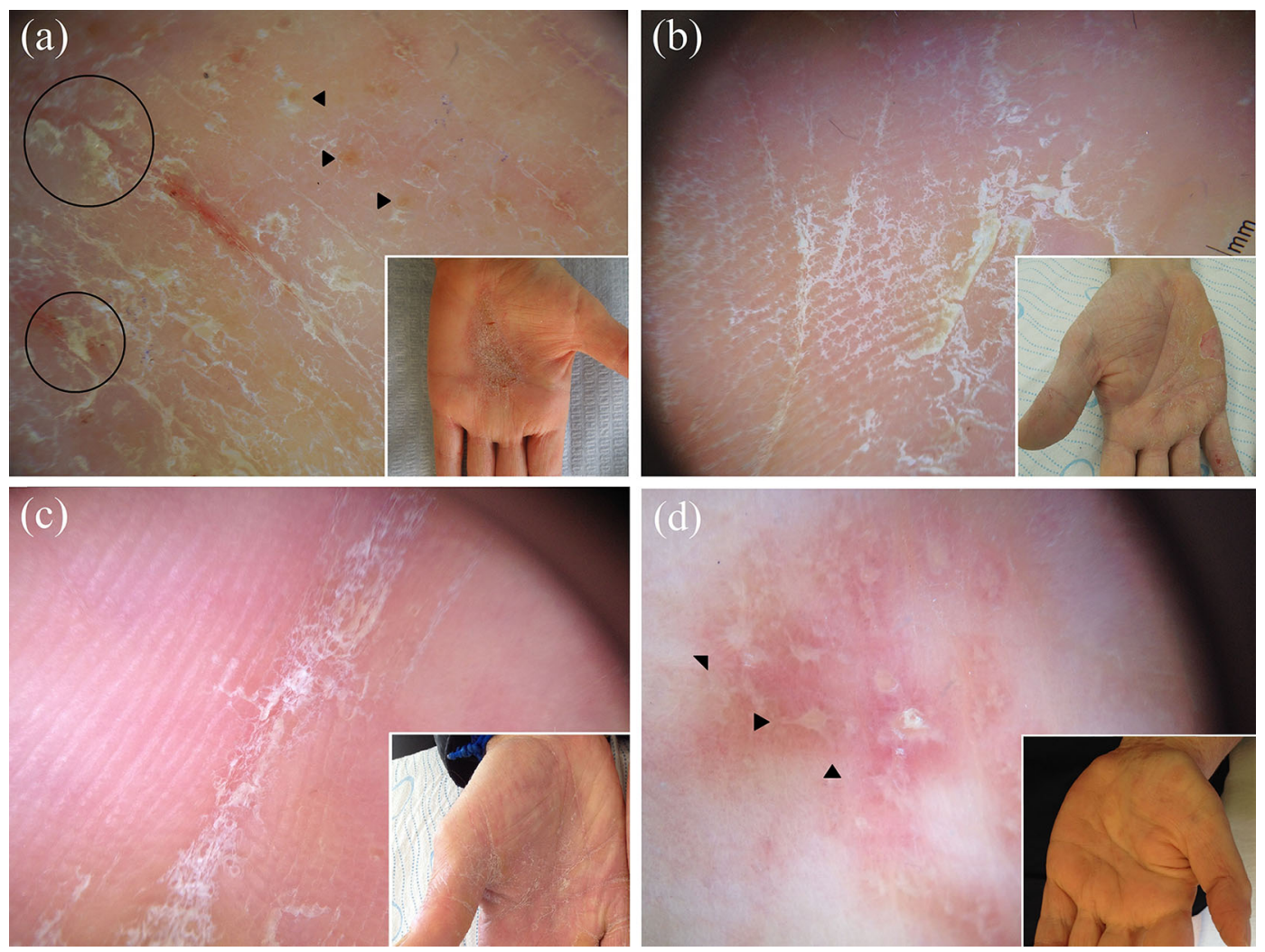

Fig. 5 Dermoscopy of chronic hand eczema typically reveals sparse whitish scales, yellowish scaling (black circles) and orangish dots/globules (black arrowheads), while palmar psoriasis and tinea manuum respectively display diffuse white scaling (b) and white scales mainly

white scales typically distributed in a diffuse pattern (and only infrequently showing patchily or central distribution) (Fig. 5b) $[23,28,85]$. Dotted vessels, which are regularly distributed (and only rarely in rings or patchy-distributed), may also be visible quite commonly when using a fluid interface (which reduce the scaling) [23]; focal yellowish scales are an additional but very rare finding $[23,28]$.

\section{Keratoderma due to Mycosis Fungoides (Level of Evidence: V-CR)}

The most characteristic dermoscopic finding of keratoderma due to mycosis fungoides consists

localised in the skin furrows (c). Dermoscopic examination of a case of palmar lichen planus shows roundish yellowish areas, some of which display peripheral projections in a star-like appearance (black arrowheads) over a purplish background (d)

of relatively large amber scales over a white-to-pinkish background; sparse whitish scales and several non-specific reddish fissures are also visible [85].

\section{Keratoderma due to Pityriasis Rubra Pilaris} (Level of Evidence: V-CR)

The dermoscopic hallmark of keratoderma resulting from pityriasis rubra pilaris is the presence of patchily distributed, homogeneous, structureless orange areas presenting different sizes; unspecific whitish scaling may also be observed [85]. 
Tinea Manuum (Level of Evidence: V-PO)

From a dermoscopic point of view, tinea manuum displays whitish scaling distributed in a characteristic pattern, i.e. mainly localised in the physiologic palmar creases (Fig. 5c) (personal observations).

\section{Palmar Lichen Planus (Level of Evidence:} V-PO)

Palmar lichen planus is typically characterised by roundish yellowish areas often having peripheral projections that may create a star-like appearance; a purplish background is sometimes visible (Fig. 5d) (personal observations).

\section{Aquagenic Palmar Keratoderma (Level of Evidence: $\mathrm{V}-\mathrm{CR}$ )}

Dermoscopy of aquagenic palmar keratoderma shows large yellow well-defined globules not affecting dermatoglyphs [86] or simply enlargement of the sweat duct pores when compared with a normal-looking palmar skin area $[87,88]$.

\section{SCLERO-ATROPHIC DERMATOSES}

\author{
Necrobiosis Lipoidica (Level of Evidence: \\ III)
}

Dermoscopy of necrobiosis lipoidica lesions typically shows comma-shaped (incipient lesions), network-shaped/hairpin-like (more developed lesions) or elongated, branching and focussed serpentine (advanced lesions) vessels over a yellowish-orange/ whitish-pinkish background (with or without reddish areas) (Fig. 6a) [89-93]. Additional findings include patchy pigmented reticulum, yellow crusting and ulceration [89-93].

\section{Morphea (Level of Evidence: IV)}

The most specific dermoscopic feature of morphea consists of whitish fibrotic beams, which are frequently crossed by linear branching vessels (Fig. 6b) [94-96]; pigment network-like structures are also often evident, while "comedo-like openings" and whitish patches are less commonly seen [94-96].
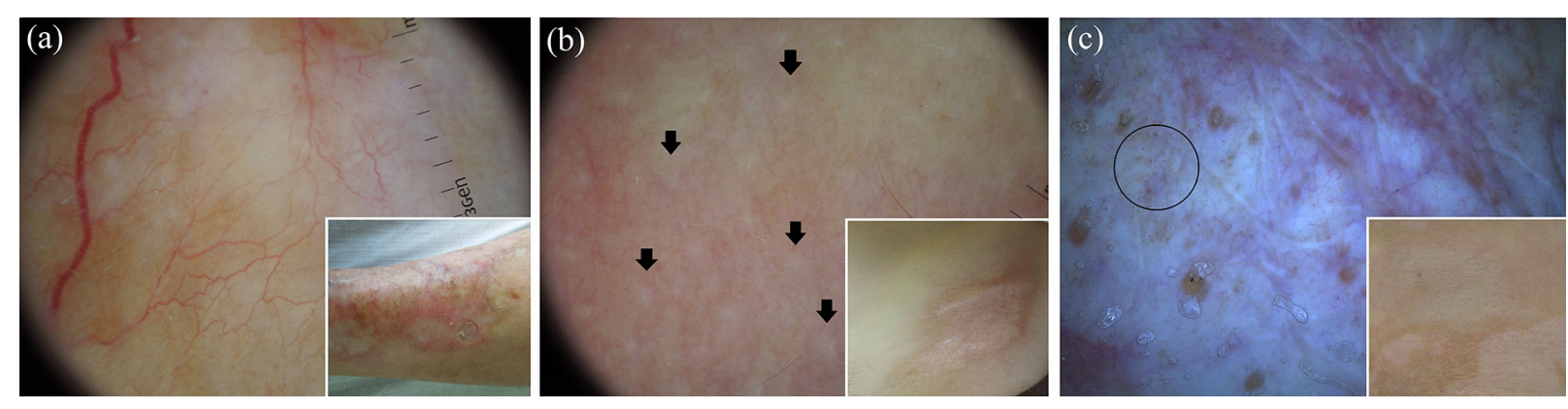

Fig. 6 Dermoscopic examination of an advanced lesion of necrobiosis lipoidica reveals elongated, branching and focussed serpentine vessels over a yellowish-orange/whitish background (a). Dermoscopy of morphea shows the typical fibrotic beams (black arrows) associated with linear branching vessels (b), while cutaneous lichen sclerosus displays several "comedo-like openings" (follicular keratotic plugs), whitish patches, dotted vessels (black circle) and delicate linear branching vessels (c) 


\section{Cutaneous Lichen Sclerosus (Level of Evidence: IV)}

The dermoscopic hallmarks of cutaneous lichen sclerosus include "comedo-like openings" (follicular keratotic plugs) and whitish patches (Fig. 6c) [94, 95, 97-100]; less common/less specific findings are represented by delicate linear branching vessels, fibrotic beams, grey dots, purpuric spots, pigment network-like structures, non-branching vessels (comma-like, hairpin and/or dotted), fine whitish scaling and chrysalis structures [94, 95, 97-100].

\section{HYPOPIGMENTED MACULAR DISEASES}

\section{Extragenital Guttate Lichen Sclerosus (Level of Evidence: IV)}

See the section "Sclero-atrophic dermatoses".

\section{Achromic Pityriasis Versicolor (Level of Evidence: V-PO)}

Dermoscopy of achromic/hypochromic lesions of pityriasis versicolor usually shows a fairly demarcated white area with fine scales that are commonly localised in the skin furrows (Fig. 7a), similarly to hyperpigmented lesions [101].

\section{Guttate Vitiligo (Level of Evidence: V-CSS)}

The most common/typical dermoscopic features of guttate vitiligo include a well-demarcated, dense/glowing, white area and perifollicular hyperpigmentation (which is more frequently seen in repigmenting or progressing lesions than stable lesions) (Fig. 7b) [102-104]. Other possible findings include perilesional hyperpigmentation, a reversed pigmentary network, reticular pigmentation and telangiectasias [102-104].

\section{Idiopathic Guttate Hypomelanosis (Level of Evidence: V-CSS)}

Dermoscopic examination of idiopathic guttate hypomelanosis displays two main aspects, i.e. the "cloudy sky-like" pattern (multiple small areas coalescing into irregular/polycyclic macules, with several white shades and both well- and ill-defined edges, surrounded by patchy hyperpigmented network) and the "cloudy" pattern (well or ill-defined roundish homogeneous whitish areas surrounded by patchy hyperpigmented network) (Fig. 7c) [101, 105].

\section{Progressive Macular Hypomelanosis (Level of Evidence: V-PO)}

Progressive macular hypomelanosis is dermoscopically characterised by an ill-defined whitish area without scaling [101].

\section{Postinflammatory Hypopigmentation} (Level of Evidence: V-CSS, PO)

Postinflammatory macular hypopigmentations often present some dermoscopic findings typical of the original lesions, e.g. non-dotted vessels/orangish structureless areas in pityriasis lichenoides [1, 40], dotted vessels in guttate psoriasis [1, 40] and star-like depigmentation in prurigo nodularis [103] (Fig. 7d), thereby assisting the retrospective diagnosis $[1,40,106]$. 

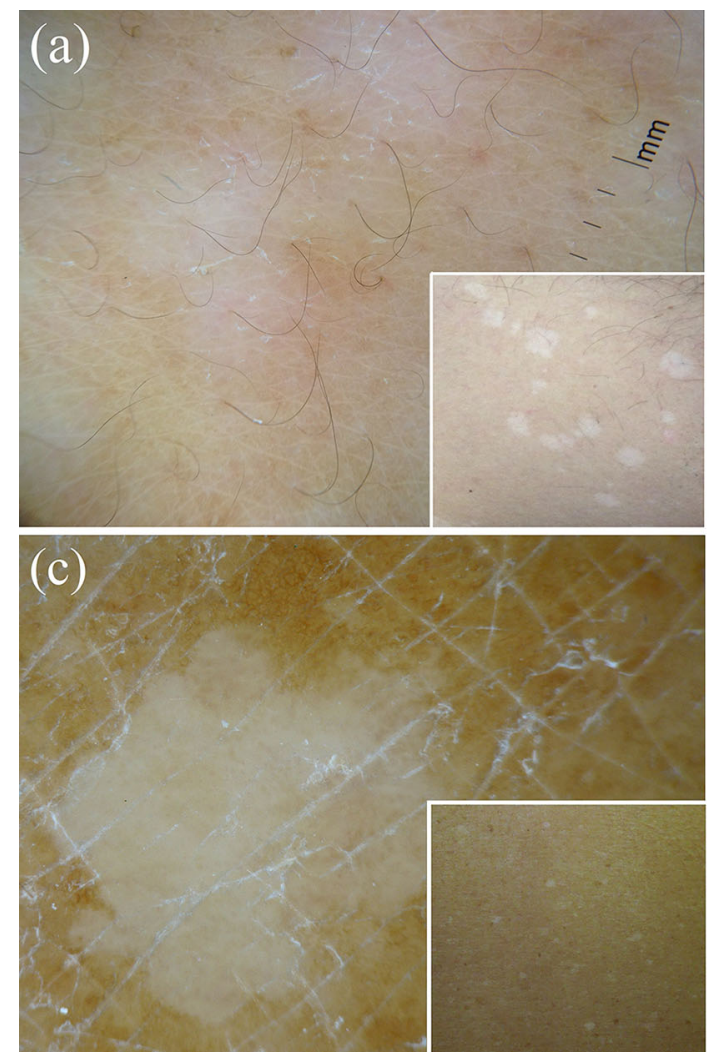

Fig. 7 Dermoscopy of achromic/hypochromic lesions of pityriasis versicolor usually shows a fairly demarcated white area with fine scales that are commonly localised in the skin furrows (a), while active lesions of guttate vitiligo typically display a well-demarcated, dense/glowing, often associated with perifollicular hyperpigmentation (black arrowheads) (b). Dermoscopic examination of idiopathic guttate hypomelanosis may show multiple small areas

\section{HYPERPIGMENTED MACULOPAPULAR DISEASES}

\section{Pityriasis Versicolor (Level of Evidence: V-CR, PO)}

Dermoscopy of hyperpigmented lesions of pityriasis versicolor shows fine whitish scaling (often localised in the skin furrows) associated with a pigmented network composed of brown stripes [107] or a diffuse, more or less

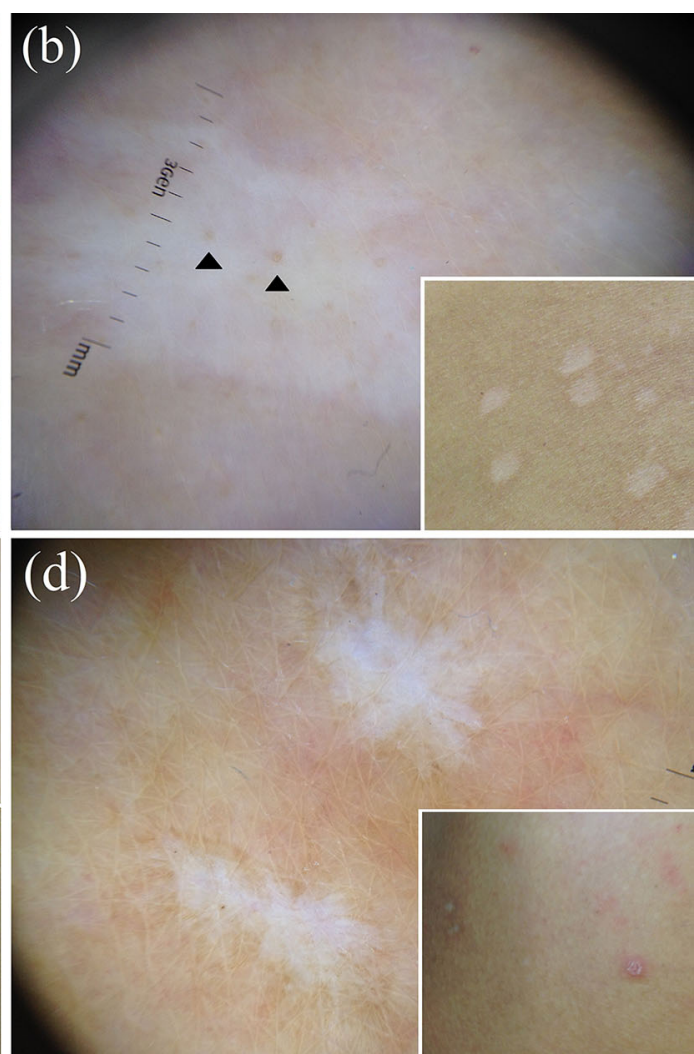

coalescing into irregular/polycyclic macules, with several white shades and both well- and ill-defined edges, surrounded by patchy hyperpigmented network ("cloudy sky-like” pattern) (c), whilst postinflammatory hypopigmentation often presents with some dermoscopic findings typical of the original lesions (in this case, the star-like arrangment typical of prurigo nodularis) (d)

homogeneous, brownish pigmentation (Fig. 8a) (personal observations).

\section{Lichen Planus Pigmentosus (Level of Evidence: V-CSS)}

The main dermoscopic patterns of lichen planus pigmentosus are represented by a diffuse, structureless, brownish pigmentation and/or fine/coarse, grey-blue/brown dots/globules (Fig. 8b); perifollicular/annular 

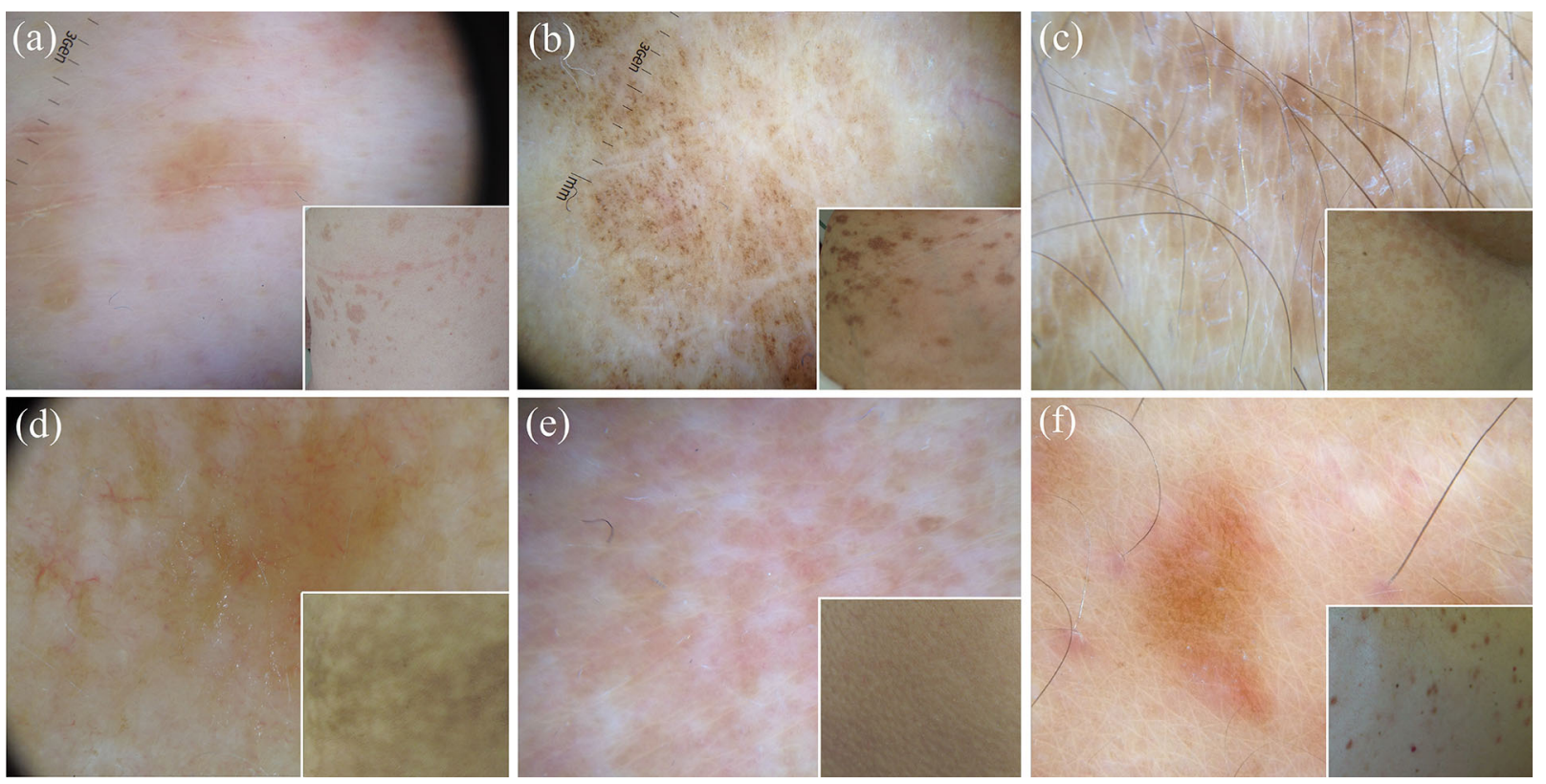

Fig. 8 Dermoscopy of hyperpigmented lesions of pityriasis versicolor often shows fine whitish scaling localised in the skin furrows associated with a diffuse brownish pigmentation (a). The most common dermoscopic finding of lichen planus pigmentosus is represented by fine/coarse, grey-blue/brown dots over a brownish background (b), while confluent and reticulated papillomatosis (Gougerot-Carteaud syndrome) displays fine whitish scaling and brownish, homogeneous, more or less defined, polygonal,

pigmentation and white dots are other less common findings [38, 39, 108, 109].

\section{Confluent and Reticulated Papillomatosis (Gougerot-Carteaud Syndrome; Level of Evidence: V—CSS, CR)}

Confluent and reticulated papillomatosis typically displays fine whitish scaling associated with brownish, homogeneous, more or less defined, polygonal, flat globules separated by whitish/pale striae creating a cobblestone appearance [110] (Fig. 8c) or brownish areas presenting a "sulci and gyri" pattern [111]. flat globules separated by whitish/pale striae creating a cobblestone pattern (c). Dermoscopic examination of pigmented lesions of erythema $a b$ igne may reveal diffuse brownish pigmentation with telangiectatic vessels/fine whitish scaling, while friction melanosis and urticaria pigmentosa typically display brownish structureless areas arranged in a reticular fashion (e) and a homogeneous light-brown blot with a pigment network (f), respectively

\section{Dowling-Degos Disease (Level of Evidence: V-CR)}

The dermoscopic aspect of Dowling-Degos disease consists of a brown star-like area/ irregular brownish projections with a hypopigmented centre over a brownish/ reddish-brown background [112-114].

\section{Erythema Ab Igne (Hyperpigmented Stage; Level of Evidence: $\mathrm{V}-\mathrm{PO}$ )}

The pigmentary stage of erythema ab igne is typically characterised by diffuse brownish pigmentation with or without telangiectatic vessels/whitish scaling (Fig. 8d) [110]. 
Primary Cutaneous Amyloidosis (Macular Amyloidosis and Lichen Amyloidosus;

Level of Evidence: V—CSS)

The most common dermoscopic finding of both macular amyloidosis and lichen amyloidosus is a central hub (which is either white or brown in the former and white in the latter) surrounded by various configurations of brownish pigmentation, including fine radiating streaks, dots, leaf-like projections and bulbous projections [115]. Additionally, in lichen amyloidosus the central hub may be replaced by a scar-like area (which may be the only feature in larger and thicker lesions) and a rim of white collarette (resembling a volcanic crater) may sometimes be appreciated [115].

Friction Melanosis (Level of Evidence:

V-CR)

The dermoscopic examination of friction melanosis typically reveals brownish structureless areas arranged in a reticular fashion (Fig. 8e) [115].

\section{Terra Firma-Forme Dermatosis (Level} of Evidence: V-CSS)

Dermoscopy of terra firma-forme dermatosis classically shows large polygonal plate-like brown scales arranged in a mosaic pattern [116].

\section{Maculopapular Cutaneous Mastocytosis} (Urticaria Pigmentosa, UP, and Telangiectasia Macularis Eruptiva Perstans, TMEP; Level of Evidence:

V-CSS, CR)

The most common dermoscopic features of UP consist of a homogeneous light-brown blot and/or pigment network (Fig. 8f), while
TMEP is mainly characterised by reticular vessels on an erythematous/brownish base ("reticular vascular" pattern), sometimes associated with a brownish network [117-121]. However, dermoscopy cannot guarantee a reliable distinction of such conditions as, albeit uncommonly, UP may display the reticular vascular pattern as well [117]. Other less frequent vascular findings visible in both UP and TMEP include sparse dotted vessels and thin and tortuous linear vessels [117-121].

\section{ITCHY PAPULONODULAR DERMATOSES}

\section{Hypertrophic Lichen Planus (Level of Evidence: V-CR)}

Dermoscopic examination of hypertrophic lichen planus lesions displays a characteristic pattern consisting of a rippled surface with comedo-like structures filled with yellow keratinous plugs and/or round corneal structures ("corn pearls") (Fig. 9a) $[14,15,35-37,108,122]$; less common features include Wickham striae, unspecific vascular findings (red globules, linear and dotted vessels), chalk-white structureless areas, scaling and central hyperpigmentation (Fig. 9a) [14, 15, 35-37, 108, 122].

\section{Prurigo Nodularis (Level of Evidence:}

V-CSS)

The dermoscopic hallmark of prurigo nodularis (both hyperkeratotic and excoriated lesions) is represented by the presence of the so-called "white starburst pattern", consisting of radially arranged whitish lines or peripheral whitish halo with some centrifugal coarse projections on a brownish and/or reddish background, 

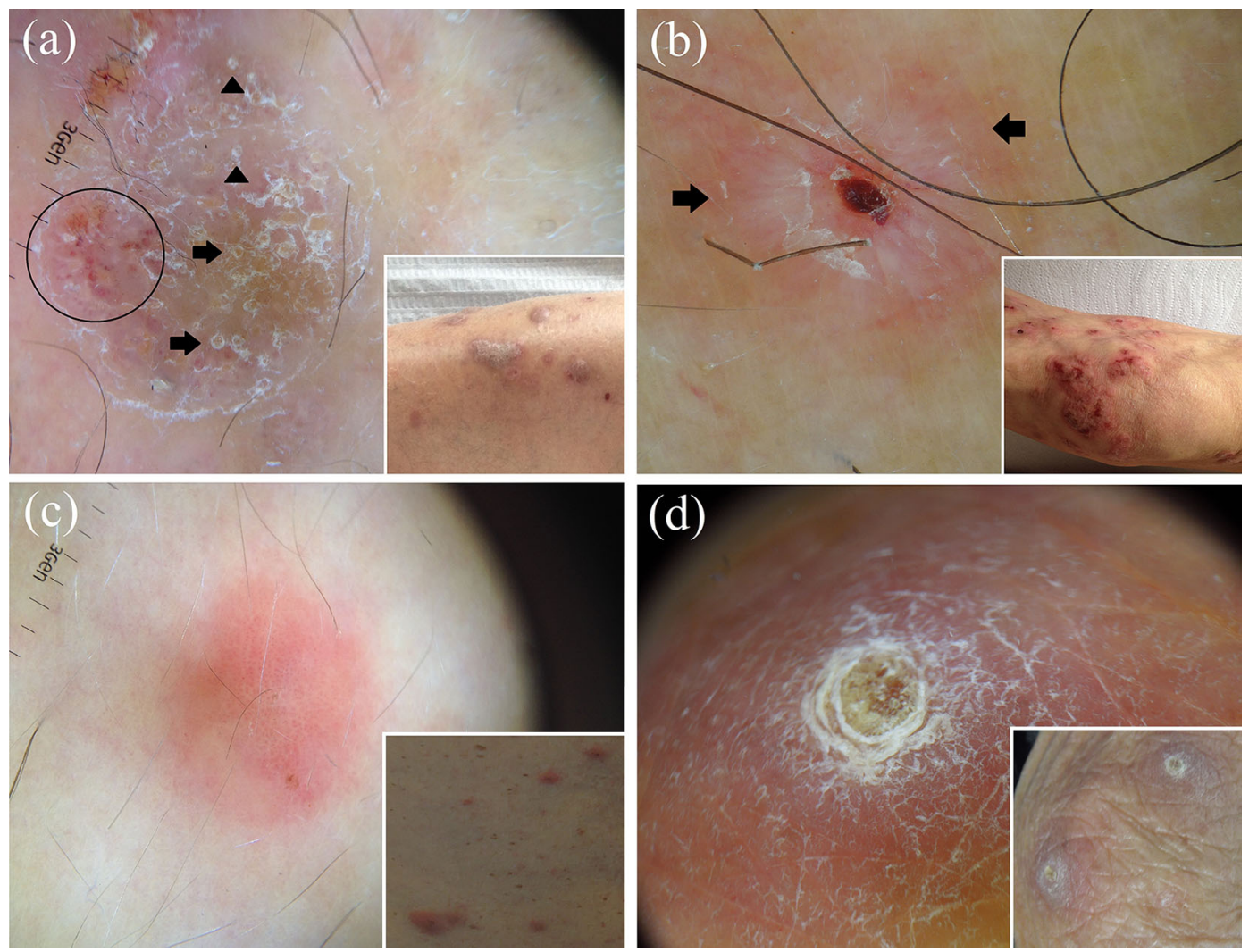

Fig. 9 Dermoscopy of hypertrophic lichen planus shows a peculiar pattern characterised by a rippled surface with comedo-like structures filled with yellow keratinous plugs (black arrows) and/or round corneal structures ("corn pearls”) (black arrowheads); some irregular dotted vessels (black circle), scaling and central hyperpigmentation are also present in this picture (a). Dermoscopy of a prurigo nodularis lesion displays the typical "white starburst pattern”, with radially arranged whitish lines (black arrows) on a brownish and/or reddish background; central erosion and scales are also present in this case (b). Although

dermoscopy of nodular scabies may often show the presence of mites ("hang glider sign”) and/or burrows ("jet with condensation trails"), it is not uncommon that the only detectable findings are nonspecific vascular features (mainly dotted vessels) (c). Dermoscopic examination of a case of reactive perforating collagenosis reveals the typical "three concentric areas" pattern, with a central round brownish-greenish/yellowish-brown structureless area, surrounded by a white keratotic collarette and an erythematous halo $(\mathbf{d})$

which may surround brown-reddish/ brown-yellowish crust(s), erosion(s) and/or hyperkeratosis/scales (Fig. 9b) [106].

\section{Nodular Scabies (Level of Evidence:} $\mathrm{V}-\mathrm{CSS}$ )

The distinctive dermoscopic sign of nodular lesions of scabies is the presence of mites ("hang

glider sign") and/or burrows ("jet with condensation trails") [123]. According to a recent study on ten patients with nodular scabies, the latter dermoscopic finding would be constantly present in such a type of scabies [123], but in our experience it may be missing (especially in extragenital sites) and unspecific vascular features (mainly dotted vessels) may be the only detectable findings (Fig. 9c) [1]. 


\section{Acquired Perforating Dermatosis (Level of Evidence: V-CR)}

The dermoscopic pattern of acquired perforating dermatosis is characterised by the presence of three concentric areas $[1,106,124,125]$, namely a central round brownish-greenish/yellowish-brown structureless area (I), surrounded by a white keratotic collarette (II) and an erythematous halo with or without dotted vessels (III) ("reactive perforating collagenosis" histological subtype) (Fig. 9d) [1, 106, 124] or bright white clods (I), centred in a structureless grey area (II), surrounded by reticular brown lines (III) ("perforating folliculitis" histological subtype) [125].

\section{ERYTHRODERMAS}

\section{Erythrodermic Psoriasis (Level}

of Evidence: V-CR)

Dermoscopy of erythrodermic psoriasis reveals a monomorphous pattern with diffusely distributed whitish scales and regularly arranged dotted/glomerular vessels on a fairly homogeneous reddish background $[29,126]$.

\section{Erythrodermic Atopic Dermatitis (Level of Evidence: V-CR)}

As for other types of eczematous dermatitis, the most important dermoscopic features of erythrodermic atopic dermatitis consist of yellowish scales/serocrusts and patchily distributed dotted vessels on a pinkish background; unspecific sparse whitish scales may also be seen [29].

\section{Erythrodermic Mycosis Fungoides (Level} of Evidence: $\mathrm{V}-\mathrm{CR}$ )

The most characteristic dermoscopic finding of erythrodermic mycosis fungoides is represented by the combination of linear vessels (some of them having a spermatozoon-like shape) and dotted vessels over a whitish-pinkish background; unspecific sparse whitish scales are also visible [29].

\section{Erythrodermic Pityriasis Rubra Pilaris}

(Level of Evidence: V-CR)

Dermoscopy of erythrodermic pityriasis rubra pilaris typically displays peculiar orange blotches and islands of nonerythematous (spared) skin displaying reticular vessels; additional features include diffuse whitish scaling and scattered dotted vessels over a reddish background [29].

\section{Erythrodermic Scabies (Level of Evidence:} V-CR)

The main dermoscopic findings of erythrodermic scabies include whitish scales and thousands of characteristic dark-brown triangular structures located at the end of whitish structureless wavy lines (delta-wing jets with contrail) over a reddish background [127].

\section{COMMON FORMS OF NONINFECTIOUS BALANITIS AND ERYTHROPLASIA OF QUEYRAT}

\section{Zoon's Plasma Cell Balanitis (Level of Evidence: V-CSS)}

The dermoscopic hallmark of Zoon's plasma cell balanitis is the presence of focal/diffuse orange-yellowish structureless areas and/or fairly focussed curved vessels (including serpentine, convoluted and chalice-shaped); 
other possible findings include linear irregular blurry vessels and dotted vessels [128].

\section{Psoriatic Balanitis}

From a dermoscopic point of view, psoriatic balanitis is characterised by the presence of regularly distributed dotted/glomerular vessels [23, 129].

\section{Seborrheic Dermatitis and Non-Specific Balanitis (Level of Evidence: $\mathrm{V}-\mathrm{PO}$ )}

Seborrheic dermatitis and non-specific balanitis usually show only linear irregular unspecific blurry vessels [128].

\section{Erythroplasia of Queyrat (Level \\ of Evidence: V-CR)}

Erythroplasia of Queyrat has been reported to show scattered glomerular vessels [130].

\section{COMMON INFLAMMATORY CICATRICIAL ALOPECIA}

\section{Discoid Lupus erythematosus (Level of Evidence: II)}

The dermoscopic hallmarks of active discoid lupus erythematosus of the scalp are represented by follicular keratotic plugs (quite large yellowish/ whitish dots) and thick arborising vessels
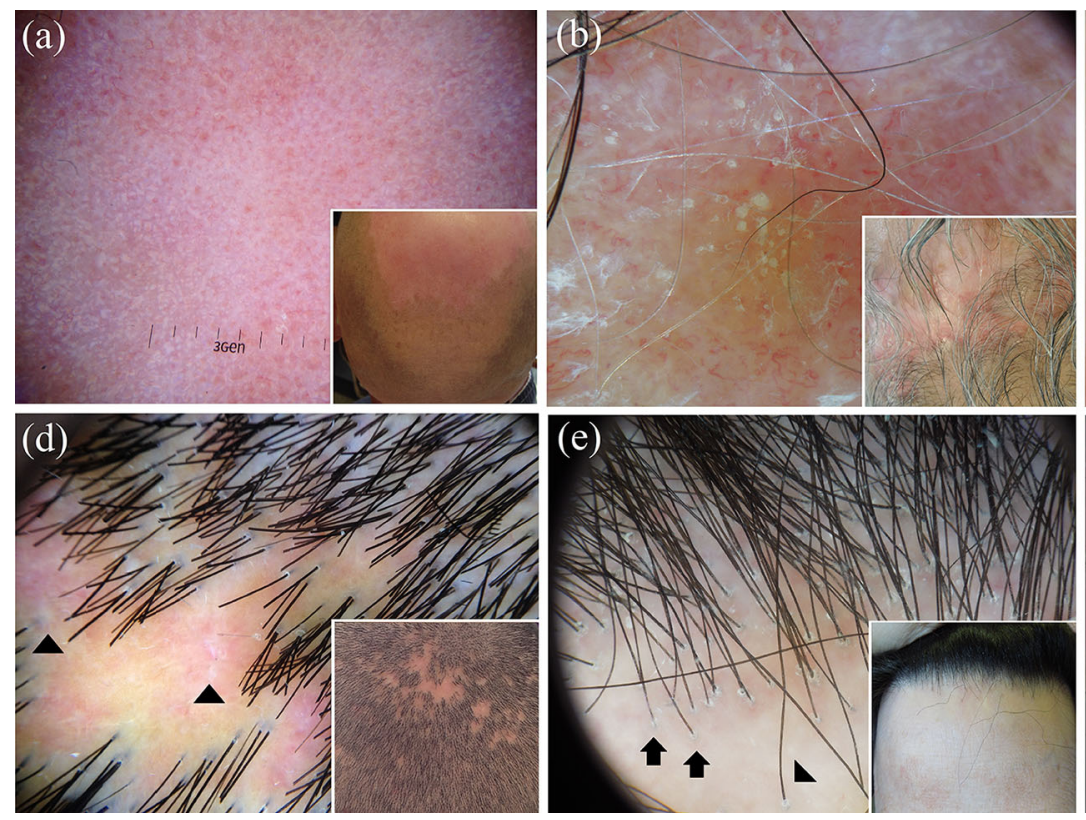
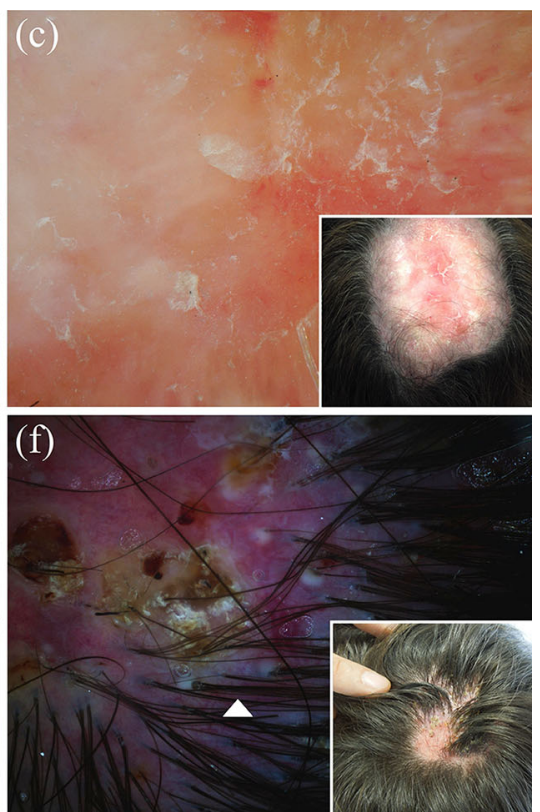

Fig. 10 Dermoscopy of discoid lupus erythematosus of the scalp varies according to the disease stage: active lesions may be mainly characterised by red dots (a) or follicular keratotic plugs (quite large yellowish/whitish dots) and thick arborising vessels (b), while long-lasting lesions commonly display loss of follicular openings, white areas and thin vessels (c). The main dermoscopic hallmarks of active lichen planopilaris are perifollicular scales; characteristic (but not pathognomonic) white dots (fibrotic white dots) (black arrowheads) and a reddish background are also present in less active areas in this case $(\mathbf{d})$.
Dermoscopic examination of a case of frontal fibrosing alopecia reveals minor perifollicular scaling with an aflegmasic (ivory white to ivory beige) surrounding background; follicular openings with only one hair at the hair-bearing margin (black arrows) and lonely hair (black arrowhead) are also visible (e). Classic dermoscopic appearance of active folliculitis decalvans showing follicular pustules, yellow discharge, crusts and characteristic hair tufts that contain $>10$ hair shafts (white arrowhead); unspecific vessels and erythema are also evident in the picture (f) 
(Fig. 10a, b) [131-137]; additional findings include fine interfollicular scaling, blue-grey dots, scattered brown discolouration and red dots (Fig. 10a) [131-137]. Thin arborising vessels emerging from the yellow dots ("red spider in a yellow dot") are considered peculiar of late, prefibrotic lesions [133], while pink areas, loss of follicular openings, white areas and branching vessels are typical of long-lasting lesions (Fig. 10c) [131, 133-137].

\section{Lichen Planopilaris (Level of Evidence: II)}

The main dermoscopic features of active lichen planopilaris are perifollicular scales, which typically migrate along the hair shaft and form a tubular structure covering the proximal portion of the emerging hair shaft ("collar-like" or "tubular" perifollicular hyperkeratosis) (Fig. 10d) [132, 133, 136-141, 149, 150]; other possible dermoscopic findings of active lesions include violaceous or violet-brown inter- or perifollicular violaceous areas (Fig. 10d), perifollicular inflammation, elongated linear blood vessels in concentric arrangement and target "blue-grey dots" [132, 133, 136-141, 149, 150]. Inactive/late lesions may show characteristic (but not pathognomonic) irregular, large white dots (fibrotic white dots) (Fig. 10d) as well as less specific findings such as acquired pili torti, loss of follicular openings, white areas, honeycomb/ scattered hyperpigmentation, milky red areas (strawberry ice cream colour) and small hair tufts of 5-9 hairs [132, 133, 136-141, 149, 150].

\section{Frontal Fibrosing Alopecia (Level of Evidence: II)}

The most common dermoscopic findings in frontal fibrosing alopecia include a lack of follicular openings and minor perifollicular scaling [131, 132, 137, 140-144]; additionally, perifollicular erythema may be seen but the surrounding background is usually aflegmasic (ivory white to ivory beige) (Fig. 10e) [131, 132, 137, 140-144]. Interestingly, there is often a strong predominance of follicular openings with only one hair at the hair-bearing margin and lonely hair may be observed (Fig. 10e) [131, 132, 137, 140-144]. Fine arborising vessels and perifollicular brown or brown-violet areas may sometimes be visible [131, 132, 137, 140-144].

\section{Folliculitis Decalvans (Level of Evidence:}

II)

The most characteristic dermoscopic feature of folliculitis decalvans is the presence of hair tufts that contain $>10$ hair shafts (Fig. 10f), which are often surrounded by a band of yellowish scales (yellowish tubular scaling) and by perifollicular epidermal hyperplasia (which may be arranged in a starburst pattern) at their base [132, 133, 137, 145-148]; other peculiar findings in active folliculitis decalvans include follicular pustules and yellow discharge and crusts (Fig. 10f) [132, 133, 137, 145-149]. A perifollicular concentration of blood vessels (elongated loops/coiled vessels) and a perifollicular erythema arranged in a starburst pattern may also be visible [132, 133, 137, 145-147, 149]. In long-lasting lesions, ivory-white and milky-red areas without follicular orifices predominate [145].

\section{COMMON NONSCARRING ALOPECIAS}

\section{Alopecia Areata (Level of Evidence: II)}

The most characteristic findings of active alopecia areata include black dots, 
micro-exclamation mark hairs, broken hairs, tapered hairs, monilethrix-like hairs and trichorrhexis nodosa, while long-standing inactive disease is mainly characterised by yellow dots and vellus hairs (Fig. 11a) [131, 139, 151-158]. The main signs of regrowing consist of upright and regularly coiled (circle and/or pigtail) hairs [131, 139, 151-158]. Less specific/less common features of active stages include tulip hairs and zigzag hairs [151, 152].
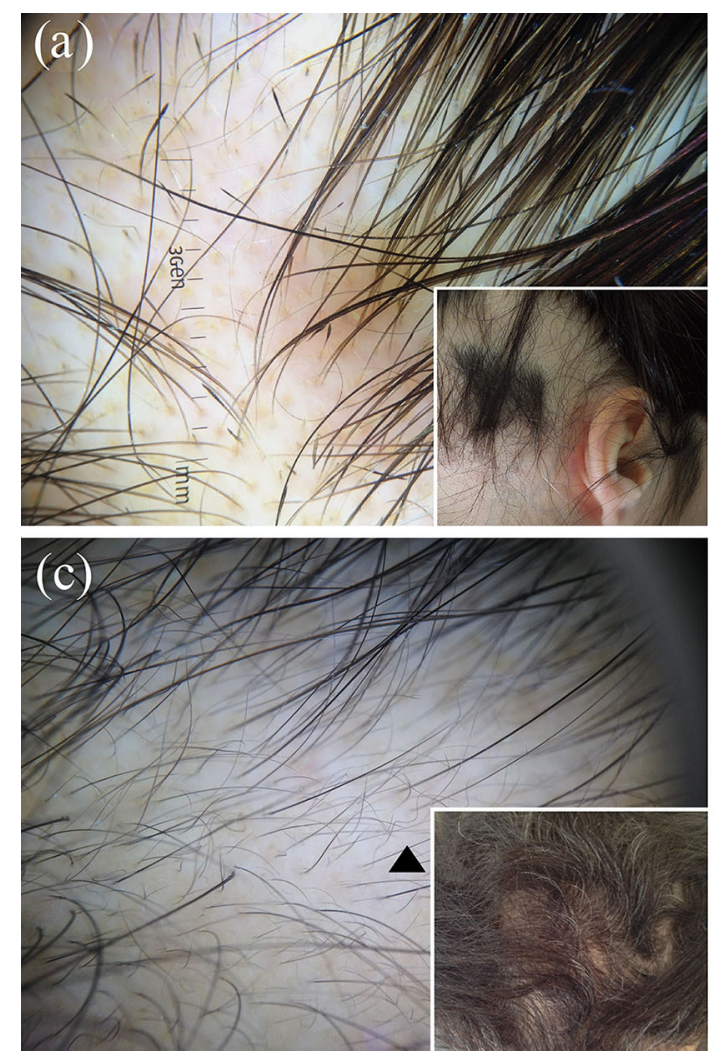

Fig. 11 Dermoscopic examination of a case of active alopecia areata shows black dots and micro-exclamation mark hairs; regular yellow dots are also evident $(\mathbf{a})$, while dermoscopy of trichotillomania reveals a chaotic pattern of diverse findings related to hair fracturing, including (in this case) hairs broken at different lengths, black dots, flame-like hairs (white arrow), tulip-like hairs (short hairs with darker, tulip-shaped ends white arrowhead) and V-sign (two or more hairs emerging from one follicular unit that are broken at the same level black arrowhead)

\section{Trichotillomania (Level of Evidence: II)}

Dermoscopy of trichotillomania often reveals a chaotic pattern of diverse findings related to hair fracturing [151, 159]. The most peculiar features include hairs broken at different lengths, short hairs with trichoptilosis ("split ends"), irregular coiled hairs, amorphous hair residues, black dots, flame-like hairs, tulip-like hairs (short hairs with darker, tulip-shaped ends) and V-sign (two or more hairs emerging

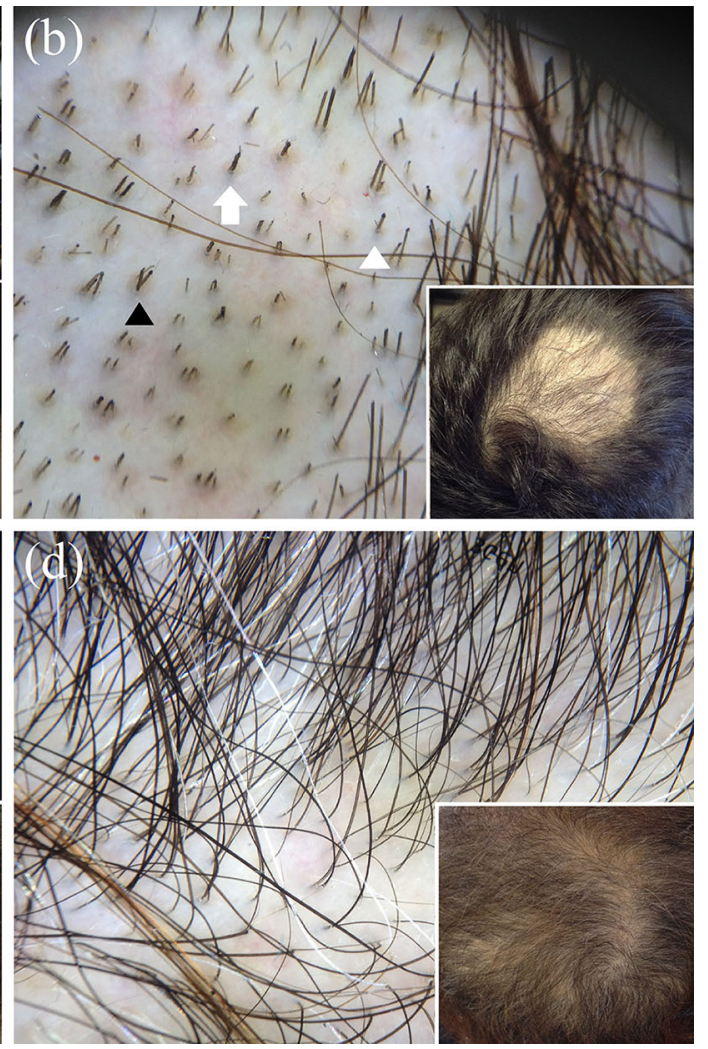

(b). Dermoscopy of androgenetic alopecia typically shows hair shaft thickness heterogeneity, a large number of follicular units with only one emerging hair shaft, and an increased proportion of thin and vellus hairs $(>10 \%$ of the hairs); wavy hairs are also visible (black arrowhead) (c). The most indicative dermoscopic clue of telogen effluvium is the lack of features typical of other diseases; empty hair follicles and follicular units with only one hair are also evident in this case of chronic telogen effluvium (d) 
from one follicular unit that are broken at the same level) (Fig. 11b) [131, 139, 151, 156, 159-163]. Less common/less specific findings are tapered hairs, follicular microhemorrhages, micro-exclamation mark hairs and upright regrowing hairs [151, 159-163].

\section{Androgenetic Alopecia (Level of Evidence: IV)}

The main dermoscopic features of androgenetic alopecia include hair shaft thickness heterogeneity, yellow dots (irregularly distributed and with a remarkable variability in size and shape), perifollicular discolouration (the peripilar sign), an increased proportion of thin and vellus hairs ( $>10 \%$ of the hairs) and a large number of follicular units with only one emerging hair shaft (Fig. 11c) [131, 132, 139, 164-168]. Thin wavy hair and honeycomb hyperpigmentation often coexist as additional, nonspecific features (Fig. 11c) [131, 132, 139, 164-168].

\section{Telogen Effluvium (Level of Evidence: IV)}

The most indicative dermoscopic clue of telogen effluvium is the lack of features typical of other diseases (Fig. 11d) [131, 139, 169]; common, but nonspecific, findings include the presence of empty hair follicles, a predominance of follicular units with only one hair, perifollicular discolouration (the peripilar sign), upright regrowing hairs (mainly acute forms) and progressive uniform hair thinning (chronic forms) (Fig. 11d) [131, 139, 169]. There is no significant difference between the findings in the frontal area and those in the occipital area, which differentiates telogen effluvium from androgenetic alopecia; however, it is important to underline that both disorders may coexist $[131,139,169]$.

\section{COMMON SCALING DISORDERS OF THE SCALP}

\author{
Tinea Capitis (Level of Evidence: II)
}

The main dermatoscopic features of tinea capitis are represented by "comma" hair (c-shaped hair shaft with a sharp, slanting end and homogeneous thickness), "corkscrew" hair (twisted or coiled, short, broken hair fragments), "zigzag" hair (hair shaft bent at multiple points) and "Morse code" hair [presence of multiple transverse bands (gaps) throughout the hair shaft] (Fig. 12a) [151, 170-187]. Other nonspecific trichoscopic findings in TC include broken and dystrophic hairs, i-hair, black dots, yellowish dots, erythema, scaling, pustules, elongated blood vessels, tufted hair and large yellowish wax-coloured perifollicular areas (favus) [151, 170-187].

\section{Scalp Psoriasis (Level of Evidence: III)}

The most indicative dermoscopic features of psoriasis of the scalp are represented by red dots and red globules as well as (with a lower specificity) signet ring vessels, red loops, white scales, punctate haemorrhages and hidden hairs (Fig. 12b) [138, 188-190]. Additional (but unspecific) findings include other vascular structures, pigmentations (perifollicular pigmentation, honeycomb pigment pattern and brown dots) and white/yellow dots [138, 188-190] .

\section{Seborrheic Dermatitis (Level of Evidence: III)}

The most characteristic dermoscopic findings of seborrheic dermatitis of the scalp consist of arborising vessels [138, 188-190]; additional 

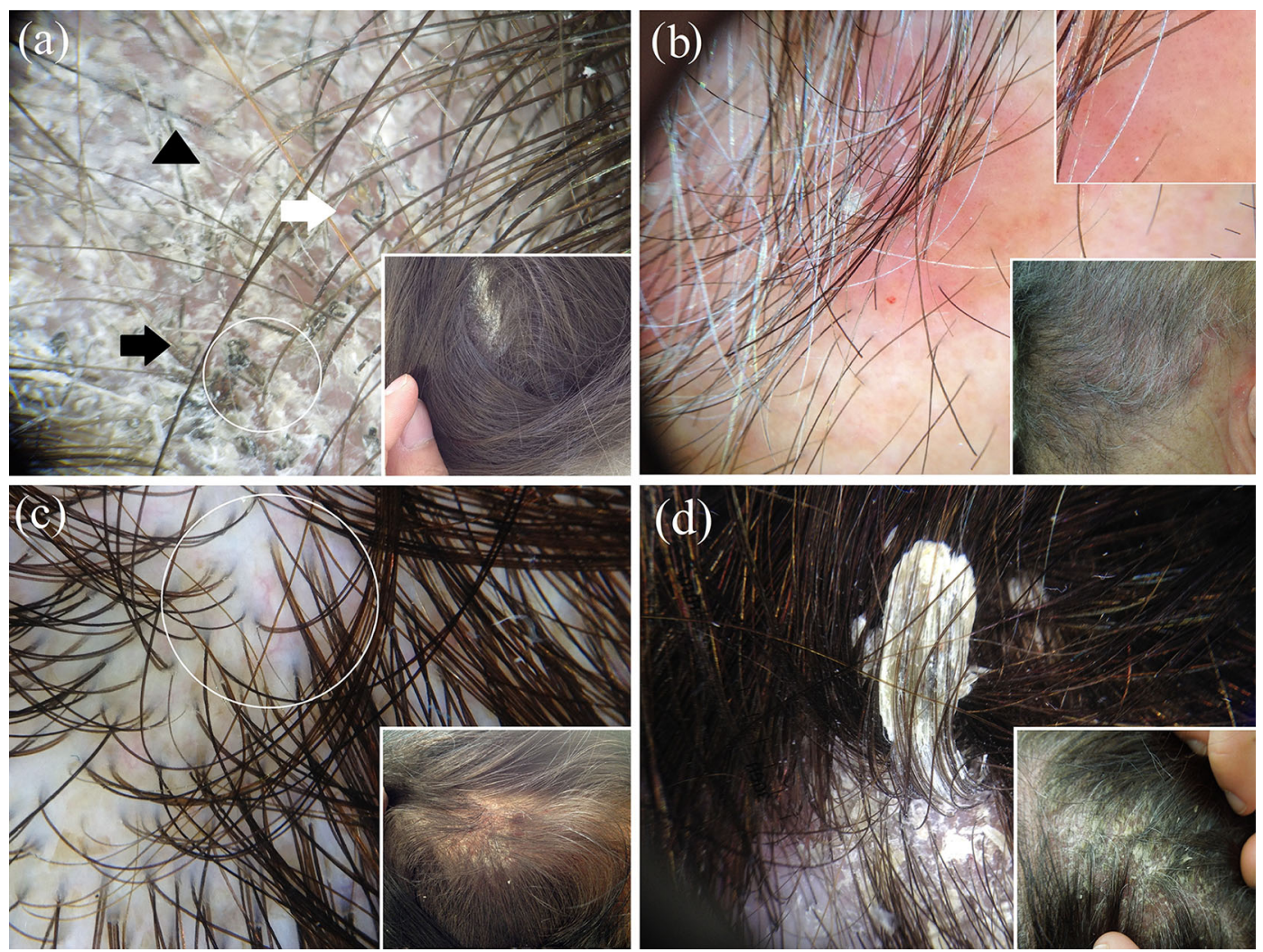

Fig. 12 Dermoscopic examination of a case of tinea capitis displays scaling and the peculiar "comma" hair (white arrow), "corkscrew" hair (white circle), "zigzag" hair (black arrow) and "Morse code" hair (black arrowhead) (a). Dermoscopy of scalp psoriasis reveals the typical dotted vessels (magnified in the upper-right box) and white scales; a haemorrhagic spot is also evident (b). Differently from

indicative features are yellowish scaling, featureless areas (structureless red areas), honeycomb pigment and comma vessels (Fig. 12c) [138, 188-190]. Less specific finding include other vascular structures, pigmentations (perifollicular pigmentation, honeycomb pigment pattern and brown dots) and white/yellow dots [138, 188-190].

\section{Pityriasis Amiantacea (Level of Evidence:} V-CR)

Dermoscopy of pityriasis amiantacea typically displays diffuse white scaling and the

psoriasis, scalp seborrhoeic dermatitis shows yellowish scales and the characteristic arborising vessels (white circle) (c). Dermoscopic examination of pityriasis amiantacea displays diffuse white scaling and the characteristic compact white keratotic material adhering to a tuft of hair (asbestos-like scale) (d)

characteristic compact white keratotic material adhering to a tuft of hair (asbestos-like scale) (Fig. 12d) [191].

\section{CONCLUSIONS}

Dermoscopy may be a helpful auxiliary tool in assisting the the noninvasive recognition/ differential diagnosis of several "general" dermatoses by magnifying both surface structures and subsurface features that are invisible to the unaided eye and reflect the different histopathological background of each condition. Importantly, this article 
should be read with a critical eye as it presents three limitations: (1) the comparative analysis of several dermatoses is not the result of direct comparative studies but has been made merely considering the dermoscopic appearance of each condition; (2) the dermoscopic description of some considered diseases is based on limited observations; (3) the level of evidence assigned to each dermatosis is based on the study/studies showing the best evidence available, so some of the reported dermoscopic findings might come from works with a lower level of evidence. Of note, in this analysis, we also considered studies lacking strong evidence as there is a growing recognition that observational studies (even case series, case reports and anecdotes) may provide worthy information, especially if they are properly supported by mechanism-based reasoning (e.g. dermoscopic-pathological correlations) [192-194]. Anyway, further high-quality, prospective, blinded, controlled investigations are needed to better characterise the use of dermoscopy in general dermatology.

\section{ACKNOWLEDGMENTS}

We are extremely grateful to Dr. Angelo Piccirillo for providing us with Fig. $4 d$ and Prof. Pasquale Patrone for the outstanding encouragement to write this article. No funding or sponsorship was received for this study or publication of this article. All named authors meet the International Committee of Medical Journal Editors (ICMJE) criteria for authorship for this manuscript, take responsibility for the integrity of the work as a whole and have given final approval for the version to be published.
Disclosures. Enzo Errichetti and Giuseppe Stinco declare no conflict of interest.

Compliance with Ethics Guidelines. The article is based on previously conducted studies and does not contain any new studies with human or animal subjects performed by any of the authors.

Open Access. This article is distributed under the terms of the Creative Commons Attribution-NonCommercial 4.0 International License (http://creativecommons.org/licenses/ by-nc/4.0/), which permits any noncommercial use, distribution, and reproduction in any medium, provided you give appropriate credit to the original author(s) and the source, provide a link to the Creative Commons license, and indicate if changes were made.

\section{REFERENCES}

1. Errichetti E, Stinco G. The practical usefulness of dermoscopy in general dermatology. G Ital Dermatol Venereol. 2015;150:533-46.

2. Lallas A, Giacomel J, Argenziano G, et al. Dermoscopy in general dermatology: practical tips for the clinician. Br J Dermatol. 2014;170:514-26.

3. Lallas A, Zalaudek I, Argenziano G, et al. Dermoscopy in general dermatology. Dermatol Clin. 2013;31:679-94.

4. Zalaudek I, Argenziano G, Di Stefani A, et al. Dermoscopy in general dermatology. Dermatology. 2006;212:7-18.

5. Micali G, Lacarrubba F, Massimino D, Schwartz RA. Dermatoscopy: alternative uses in daily clinical practice. J Am Acad Dermatol. 2011;64:1135-46.

6. Zalaudek I, Lallas A, Moscarella E, Longo C, Soyer HP, Argenziano G. The dermatologist's stethoscope-traditional and new applications of dermoscopy. Dermatol Pract Concept. 2013;3:67-71.

7. Miteva M, Tosti A. Hair and scalp dermatoscopy. J Am Acad Dermatol. 2012;67:1040-8. 
8. Lencastre A, Lamas A, Sá D, Tosti A. Onychoscopy. Clin Dermatol. 2013;31:587-93.

9. Oxford Centre for Evidence-Based Medicine. "The Oxford 2011 Levels of Evidence". Available at: http://www.cebm.net/index.aspx?o=5653. Accessed 8 August 2016.

10. The Joanna Briggs Institute Reviewers' Manual 2015. "The systematic review of studies of diagnostic test accuracy". Available at: http://www.joannabriggs. org/assets/docs/sumari/Reviewers-Manual_The-syst ematic-review-of-studies-of-diagnostic-test-accuracy. pdf. Accessed 8 August 2016.

11. Rutjes AW, Reitsma JB, Vandenbroucke JP, Glas AS, Bossuyt PM. Case-control and two-gate designs in diagnostic accuracy studies. Clin Chem. 2005;51:1335-41.

12. Porta M, editor. A dictionary of epidemiology. 6th ed. New York: Oxford University Press; 2014.

13. Lallas A, Kyrgidis A, Tzellos TG, et al. Accuracy of dermoscopic criteria for the diagnosis of psoriasis, dermatitis, lichen planus and pityriasis rosea. Br J Dermatol. 2012;166:1198-205.

14. Vázquez-López F, Manjón-Haces JA, Maldonado-Seral C, Raya-Aguado C, Pérez-Oliva N, Marghoob AA. Dermoscopic features of plaque psoriasis and lichen planus: new observations. Dermatology. 2003;207:151-6.

15. Zalaudek I, Argenziano G. Dermoscopy subpatterns of inflammatory skin disorders. Arch Dermatol. 2006;142:808.

16. Lallas A, Apalla Z, Karteridou A, Lefaki I. Dermoscopy for discriminating between pityriasis rubra pilaris and psoriasis. J Dermatol Case Rep. 2013;7:20-2.

17. Moscarella E, Longo C, Zalaudek I, Argenziano G, Piana S, Lallas A. Dermoscopy and confocal microscopy clues in the diagnosis of psoriasis and porokeratosis. J Am Acad Dermatol. 2013;69:e231-3.

18. Errichetti E, Maione V, Pegolo E, Stinco G. Dermoscopy: a useful auxiliary tool in the diagnosis of type 1 segmental Darier's disease. Dermatol Pract Concept. 2016;6:53-5.

19. Vázquez-López F, Kreusch J, Marghoob AA. Dermoscopic semiology: further insights into vascular features by screening a large spectrum of nontumoral skin lesions. $\mathrm{Br} \mathrm{J}$ Dermatol. 2004;150:226-31.

20. Xu C, Liu J, Chen D, Liu Y, Sun Q. Roles of dermoscopy in differential diagnosis of psoriasis and eczema. Zhonghua Yi Xue Za Zhi. 2014;94:2833-7.

21. Lallas A, Apalla Z, Tzellos T, Lefaki I. Dermoscopy in clinically atypical psoriasis. J Dermatol Case Rep. 2012;6:61-2.

22. Vázquez López F, González-Lara L, Martin JS, Argenziano G. Dr K. Holubar (1936-2013). Teaching with dermoscopy: revealing the subsurface morphology of Auspitz's sign and psoriasis. Int J Dermatol. 2014;53:e322-4.

23. Lallas A, Apalla Z, Argenziano G, et al. Dermoscopic pattern of psoriatic lesions on specific body sites. Dermatology. 2014;228:250-4.

24. Lacarrubba F, D'Amico V, Nasca MR, Dinotta F, Micali G. Use of dermatoscopy and videodermatoscopy in therapeutic follow-up: a review. Int J Dermatol. 2010;49:866-73.

25. Lacarrubba F, Pellacani G, Gurgone S, Verzì AE, Micali G. Advances in non-invasive techniques as aids to the diagnosis and monitoring of therapeutic response in plaque psoriasis: a review. Int J Dermatol. 2015;54:626-34.

26. Lallas A, Argenziano G, Apalla Z, et al. Dermoscopic patterns of common facial inflammatory skin diseases. J Eur Acad Dermatol Venereol. 2014;28:609-14.

27. Vázquez-López F, Zaballos P, Fueyo-Casado A, Sánchez-Martín J. A dermoscopy subpattern of plaque-type psoriasis: red globular rings. Arch Dermatol. 2007;143:1612.

28. Errichetti E, Stinco G. Dermoscopy in differential diagnosis of palmar psoriasis and chronic hand eczema. J Dermatol. 2016;43:423-5.

29. Errichetti E, Piccirillo A, Stinco G. Dermoscopy as an auxiliary tool in the differentiation of the main types of erythroderma due to dermatological disorders. Int J Dermatol. 2016; . doi:10.1111/ijd. 13322.

30. Navarini AA, Feldmeyer L, Töndury B, et al. The yellow clod sign. Arch Dermatol. 2011;147:1350.

31. Chuh AA. Collarette scaling in pityriasis rosea demonstrated by digital epiluminescence dermatoscopy. Australas J Dermatol. 2001;42:288-90.

32. Chuh AA. The use of digital epiluminescence dermatoscopyto identify peripheral scaling in pityriasis rosea. Comput Med Imaging Graph. 2002;26:129-34.

33. Lallas A, Apalla Z, Lefaki I, et al. Dermoscopy of early stage mycosis fungoides. J Eur Acad Dermatol Venereol. 2013;27:617-21. 
34. Errichetti E, Piccirillo A, Viola L, Stinco G. Dermoscopy of subacute cutaneous lupus erythematosus. Int J Dermatol. 2016;. doi:10.1111/ ijd.13331.

35. Vázquez-López F, Alvarez-Cuesta C, Hidalgo-García $\mathrm{Y}$, Pérez-Oliva $\mathrm{N}$. The handheld dermatoscope improves the recognition of Wickham striae and capillaries in lichen planus lesions. Arch Dermatol. 2001;137:1376.

36. Vázquez-López F, Vidal AM, Zalaudek I. Dermoscopic subpatterns of ashy dermatosis related to lichen planus. Arch Dermatol. 2010;146:110.

37. Vázquez-López F, Gómez-Díez S, Sánchez J, Pérez-Oliva N. Dermoscopy of active lichen planus. Arch Dermatol. 2007;143:1092.

38. Güngör Ş, Topal IO, Göncü EK. Dermoscopic patterns in active and regressive lichen planus and lichen planus variants: a morphological study. Dermatol Pract Concept. 2015;5:45-53.

39. Friedman P, Sabban EC, Marcucci C, Peralta R, Cabo H. Dermoscopic findings in different clinical variants of lichen planus. Is dermoscopy useful? Dermatol Pract Concept. 2015;5:51-5.

40. Errichetti E, Lacarrubba F, Micali G, Piccirillo A, Stinco G. Differentiation of pityriasis lichenoides chronica from guttate psoriasis by dermoscopy. Clin Exp Dermatol. 2015;40:804-6.

41. Stinco G, Buligan C, Errichetti E, Valent F, Patrone P. Clinical and capillaroscopic modifications of the psoriatic plaque during therapy: observations with oral acitretin. Dermatol Res Pract. 2013;2013:781942.

42. Delfino M, Argenziano G, Nino M. Dermoscopy for the diagnosis of porokeratosis. J Eur Acad Dermatol Venereol. 2004;18:194-5.

43. Zaballos P, Puig S, Malvehy J. Dermoscopy of disseminated superficial actinic porokeratosis. Arch Dermatol. 2004;140:1410.

44. Panasiti V, Rossi M, Curzio M, Bruni F, Calvieri S. Disseminated superficial actinic porokeratosis diagnosed by dermoscopy. Int $\mathrm{J}$ Dermatol. 2008;47:308-10.

45. Pizzichetta MA, Canzonieri V, Massone C, Soyer HP. Clinical and dermoscopic features of porokeratosis of Mibelli. Arch Dermatol. 2009;145:91-2.

46. Oiso N, Kawada A. Dermoscopic features in disseminated superficial actinic porokeratosis. Eur J Dermatol. 2011;21:439-40.
47. Uhara H, Kamijo F, Okuyama R, Saida T. Open pores with plugs in porokeratosis clearly visualized with the dermoscopic furrow ink test: report of 3 cases. Arch Dermatol. 2011;147:866-8.

48. Hayashi Y, Ozeki M, Ishizaki S, et al. Inguinal porokeratosis in a Japanese man. Dermatol Pract Concept. 2013;3:29-31.

49. Vargas-Laguna E, Nagore E, Alfaro A, et al. Monitoring the evolution of a localized type of porokeratosis using dermatoscopy. Actas Dermosifiliogr. 2006;97:77-8.

50. Moura FN, Thomas L, Balme B, Dalle S. Dermoscopy of lymphomatoid papulosis. Arch Dermatol. 2009; 145:966-7.

51. Errichetti E, Stinco G. Usefulness of dermoscopy in poikiloderma vasculare atrophicans/parakeratosis variegata. Eur J Dermatol. 2016;26:300-2.

52. Errichetti E, De Francesco V, Pegolo E, Stinco G. Dermoscopy of Grover's disease: variability according to histological subtype. J Dermatol. 2016;43:937-9.

53. Giacomel J, Zalaudek I, Argenziano G. Dermatoscopy of Grover's disease and solitary acantholytic dyskeratoma shows a brown, starlike pattern. Australas J Dermatol. 2012;53:315-6.

54. Sadayasu A, Maumi Y, Hayashi Y, et al. Dermoscopic features of a case of transient acantholytic dermatosis. Australas J Dermatol. 2016;. doi:10.1111/ajd.12434.

55. Marchetti MA, Fonseca M, Dusza SW, et al. Dermoscopic clues to diagnose acantholytic dyskeratosis. Dermatol Pract Concept. 2015;5:11-28.

56. Errichetti E, Stinco G, Lacarrubba F, Micali G. Dermoscopy of Darier's disease. J Eur Acad Dermatol Venereol. 2015; doi:10.1111/jdv.13238. $\mathrm{X}$.

57. Lacarrubba F, Verzì AE, Errichetti E, Stinco G, Micali G. Darier disease: dermoscopy, confocal microscopy, and histologic correlations. J Am Acad Dermatol. 2015;73:e97-9.

58. Vázquez-López F, Lopez-Escobar M, Maldonado-Seral C, Perez-Oliva N, Marghoob AA. The handheld dermoscope improves the recognition of giant pseudocomedones in Darier's disease. J Am Acad Dermatol. 2004;50:454-5.

59. Lallas A, Argenziano G, Longo C, et al. Polygonal vessels of rosacea are highlighted by dermoscopy. Int J Dermatol. 2014;53:e325-7. 
60. Rubegni P, Tataranno DR, Nami N, Fimiani $M$. Rosettes: optical effects and not dermoscopic patterns related to skin neoplasms. Australas J Dermatol. 2013;54:271-2.

61. Lallas A, Apalla Z, Lefaki I, et al. Dermoscopy of discoid lupus erythematosus. $\mathrm{Br} \mathrm{J}$ Dermatol. 2013;168:284-8.

62. Inui S, Itami S, Murakami M, Nishimoto $N$. Dermoscopy of discoid lupus erythematosus: report of two cases. J Dermatol. 2014;41:756-7.

63. Lopez-Tintos BO, Garcia-Hidalgo L, Orozco-Topete R. Dermoscopy in active discoid lupus. Arch Dermatol. 2009; 145:358.

64. Lallas A, Apalla Z, Argenziano G, Moscarella E, Longo C, Zalaudek I. Clues for differentiating discoid lupus erythematosus from actinic keratosis. J Am Acad Dermatol. 2013;69:e5-6.

65. Giacomel J, Zalaudek I, Argenziano G, Lallas A. Dermoscopy of hypertrophic lupus erythematosus and differentiation from squamous cell carcinoma. J Am Acad Dermatol. 2015;72:S33-6.

66. Pellicano R, Tiodorovic-Zivkovic D, Gourhant JY, et al. Dermoscopy of cutaneous sarcoidosis. Dermatology. 2010;221:51-4.

67. Bombonato C, Argenziano G, Lallas A, Moscarella E, Ragazzi M, Longo C. Orange color: a dermoscopic clue for the diagnosis of granulomatous skin diseases. J Am Acad Dermatol. 2015;72:S60-3.

68. Hadj I, Mernissi FZ. Dermoscopic features of sarcoidosis. Pan Afr Med J. 2014;18:111.

69. Balestri R, La Placa M, Bardazzi F, Rech G. Dermoscopic subpatterns of granulomatous skin diseases. J Am Acad Dermatol. 2013;69:e217-8.

70. Vazquez-Lopez F, Palacios-Garcia L, Gomez-Diez S, Argenziano G. Dermoscopy for discriminating between lichenoid sarcoidosis and lichen planus. Arch Dermatol. 2011;147:1130.

71. Huet P, Barnéon G, Cribier B. Cutaneous sarcoidosis: correlation between dermatopathology and dermoscopy. Ann Dermatol Venereol. 2016;143:404-6.

72. Brasiello M, Zalaudek I, Ferrara G, et al. Lupus vulgaris: a new look at an old symptom-the lupoma observed with dermoscopy. Dermatology. 2009;218:172-4.

73. Llambrich A, Zaballos P, Terrasa F, Torne I, Puig S, Malvehy J. Dermoscopy of cutaneous leishmaniasis. Br J Dermatol. 2009;160:756-61.
74. Yücel A, Günaşti S, Denli Y, Uzun S. Cutaneous leishmaniasis: new dermoscopic findings. Int J Dermatol. 2013;52:831-7.

75. Taheri AR, Pishgooei N, Maleki $M$, et al. Dermoscopic features of cutaneous leishmaniasis. Int J Dermatol. 2013;52:1361-6.

76. Ramot Y, Nanova K, Alper-Pinus R, Zlotogorski A. Zosteriform cutaneous leishmaniasis diagnosed with the help of dermoscopy. Dermatol Pract Concept. 2014;4:55-7.

77. Ayhan E, Ucmak D, Baykara SN, Akkurt ZM, Arica M. Clinical and dermoscopic evaluation of cutaneous leishmaniasis. Int J Dermatol. 2015;54:193-201.

78. Caltagirone F, Pistone G, Arico M, et al. Vascular patterns in cutaneous leishmaniasis: a videodermatoscopic study. Indian J Dermatol Venereol Leprol. 2015;81:394-8.

79. Buljan M, Zalaudek I, Massone C, Hofmann-Wellenhof R, Fink-Puches R, Arzberger E. Dermoscopy and reflectance confocal microscopy in cutaneous leishmaniasis on the face. Australas J Dermatol. 2015;. doi:10.1111/ajd.12404.

80. Dobrev HP, Nocheva DG, Vuchev DI, Grancharova RD. Cutaneous leishmaniasis-dermoscopic findings and cryotherapy. Folia Med (Plovdiv). 2015;57:65-8.

81. Caldarola G, Zalaudek I, Argenziano G, Bisceglia M, Pellicano R. Granuloma faciale: a case report on long-term treatment with topical tacrolimus and dermoscopic aspects. Dermatol Ther. 2011;24:508-11.

82. Lallas A, Sidiropoulos T, Lefaki I, Tzellos T, Sotiriou E, Apalla Z. Photoletter to the editor: dermoscopy of granuloma faciale. J Dermatol Case Rep. 2012;6:59-60.

83. Teixeira DA, Estrozi B, Ianhez M. Granuloma faciale: a rare disease from a dermoscopy perspective. An Bras Dermatol. 2013;88:97-100.

84. Segal R, Mimouni D, Feuerman H, Pagovitz O, David M. Dermoscopy as a diagnostic tool in demodicidosis. Int J Dermatol. 2010;49:1018-23.

85. Errichetti E, Stinco G. Dermoscopy as a supportive instrument in the differentiation of the main types of acquired keratoderma due to dermatological disorders. J Eur Acad Dermatol Venereol. 2016; doi:10.1111/jdv.13566.

86. Fernández-Crehuet $\mathrm{P}$, Ruiz-Villaverde R. Dermoscopic features of aquagenic syringeal 
acrokeratoderma. Int J Dermatol. 2016;. doi:10. 1111/ijd.13247.

87. Sezer E, Erkek E, Duman D, Sahin S, Cetin E. Dermatoscopy as an adjunctive diagnostic tool in aquagenic syringeal acrokeratoderma. Dermatology. 2012;225:97-9.

88. Ghosh SK, Agarwal M, Ghosh S, Dey AK. Aquagenic palmar wrinkling in two Indian patients with special reference to its dermoscopic pattern. Dermatol Online J. 2015;21:6.

89. Lallas A, Zaballos P, Zalaudek I, et al. Dermoscopic patterns of granuloma annulare and necrobiosis lipoidica. Clin Exp Dermatol. 2013;38:425-7.

90. Pellicano R, Caldarola G, Filabozzi P, Zalaudek I. Dermoscopy of necrobiosis lipoidica and granuloma annulare. Dermatology. 2013;226:319-23.

91. Conde-Montero E, Avilés-Izquierdo JA, Mendoza-Cembranos MD, Parra-Blanco V. Dermoscopy of necrobiosis lipoidica. Actas Dermosifiliogr. 2013;104:534-7.

92. Bakos RM, Cartell A, Bakos L. Dermatoscopy of early-onset necrobiosis lipoidica. J Am Acad Dermatol. 2012;66:e143-4.

93. Balestri R, La Placa M, Bardazzi F, Rech G. Dermoscopic subpatterns of granulomatous skin diseases. J Am Acad Dermatol. 2013;69:e217-8.

94. Shim WH, Jwa SW, Song $M$, et al. Diagnostic usefulness of dermatoscopy in differentiating lichen sclerous et atrophicus from morphea. J Am Acad Dermatol. 2012;66:690-1.

95. Tiodorovic-Zivkovic D, Argenziano G, Popovic D, Zalaudek I. Clinical and dermoscopic findings of a patient with co-existing lichen planus, lichen sclerosus and morphea. Eur J Dermatol. 2012;22:143-4.

96. Campione E, Paternò EJ, Diluvio L, Orlandi A, Bianchi L, Chimenti S. Localized morphea treated with imiquimod 5\% and dermoscopic assessment of effectiveness. J Dermatol Treat. 2009;20:10-3.

97. Garrido-Ríos AA, Alvarez-Garrido H, Sanz-Muñoz C, Aragoneses-Fraile H, Manchado-López P, Miranda-Romero A. Dermoscopy of extragenital lichen sclerosus. Arch Dermatol. 2009;145:1468.

98. Lacarrubba F, Dinotta F, Nasca MR, Fabbrocini G, Micali G. Localized vascular lesions of the glans in patients with lichen sclerosus diagnosed by dermatoscopy. G Ital Dermatol Venereol. 2012;147:510-1.
99. Horcajada-Reales C, Campos-Domínguez M, Conde-Montero E, Parra-Blanco V, Suárez-Fernández R. Comedo-like openings in dermoscopy: an essential diagnostic clue for lichen sclerosus, even in children. J Am Acad Dermatol. 2015;72:S4-5.

100. Lacarrubba F, Pellacani G, Verzì AE, Pippione M, Micali G. Extragenital lichen sclerosus: clinical, dermoscopic, confocal microscopy and histologic correlations. J Am Acad Dermatol. 2015;72:S50-2.

101. Errichetti E, Stinco G. Dermoscopy of idiopathic guttate hypomelanosis. J Dermatol. 2015;42:1118-9.

102. Chuh AA, Zawar V. Demonstration of residual perifollicular pigmentation in localized vitiligo-a reverse and novel application of digital epiluminescence dermoscopy. Comput Med Imaging Graph. 2004;28:213-7.

103. Meng R, Zhao G, Cai RK, Xiao M, Jiang Z. Application of polarized light dermoscopy in the early diagnosis of vitiligo and its differential diagnosis from other depigmented diseases. Chin J Dermatol. 2009;42:810-3.

104. Thatte SS, Khopkar US. The utility of dermoscopy in the diagnosis of evolving lesions of vitiligo. Indian J Dermatol Venereol Leprol. 2014;80:505-8.

105. Ankad BS, Beergouder SL. Dermoscopic evaluation of idiopathic guttate hypomelanosis: a preliminary observation. Indian Dermatol Online J. 2015;6:164-7.

106. Errichetti E, Piccirillo A, Stinco G. Dermoscopy of prurigo nodularis. J Dermatol. 2015;42:632-4.

107. Zhou H, Tang XH, De Han J, Chen MK. Dermoscopy as an ancillary tool for the diagnosis of pityriasis versicolor. J Am Acad Dermatol. 2015;73:e205-6.

108. Haldar SS, Khopkar U. Dermoscopy of Lichen Planus. In: Khopkar U, Valia A, editors. Lichen Planus. 1st ed. New Delhi: Jaypee Brothers Medical Publishers; 2013. p. 148-62.

109. Murzaku EC, Bronsnick T, Rao BK. Axillary lichen planus pigmentosus-inversus: dermoscopic clues of a rare entity. Diagnosis: Lichen planus pigmentosus (LPP). J Am Acad Dermatol. 2014;71:e119-20.

110. Errichetti E, Maione V, Stinco G. Dermatoscopy of confluent and reticulated papillomatosis (Gougerot-Carteaud syndrome). J Dtsch Dermatol Ges. 2016 (in press).

111. Bernardes Filho F, Quaresma MV, Rezende FC, Kac BK, Nery JA, Azulay-Abulafia L. Confluent and 
reticulate papillomatosis of Gougerot-Carteaud and obesity: dermoscopic findings. An Bras Dermatol. 2014;89:507-9.

112. Massone C, Hofmann-Wellenhof R. Dermoscopy of Dowling-Degos disease of the vulva. Arch Dermatol. 2008;144:417-8.

113. Geissler S, Dyall-Smith D, Coras B, Guther S, Peters B, Stolz W. Unique brown star shape on dermatoscopy of generalized Dowling-Degos disease. Australas J Dermatol. 2011;52:151-3.

114. Nirmal B, Dongre AM, Khopkar US. Dermatoscopic features of hyper and hypopigmented lesions of Dowling Degos disease. Indian J Dermatol. 2016;61:125.

115. Chuang YY, Lee DD, Lin CS, et al. Characteristic dermoscopic features of primary cutaneous amyloidosis: a study of 35 cases. Br J Dermatol. 2012;167:548-54.

116. Abdel-Razek MM, Fathy H. Terra firma-forme dermatosis: case series and dermoscopic features. Dermatol Online J. 2015;21:10.

117. Vano-Galvan S, Alvarez-Twose I, De las Heras E, et al. Dermoscopic features of skin lesions in patients with mastocytosis. Arch Dermatol. 2011;147:932-40.

118. Akay BN, Kittler H, Sanli H, Harmankaya K, Anadolu R. Dermatoscopic findings of cutaneous mastocytosis. Dermatology. 2009;218:226-30.

119. Miller MD, Nery NS, Gripp AC, Maceira JP, Nascimento GM. Dermatoscopic findings of urticaria pigmentosa. An Bras Dermatol. 2013;88:986-8.

120. Gutiérrez-González E, Ginarte M, Toribio J. Cutaneous mastocytosis with systemic involvement mimicking clinical and dermatoscopically multiple melanocytic nevi. Dermatol Online J. 2011;17:15.

121. Unterstell N, Lavorato FG, Nery NS, Mann D, Alves Mde F, Barcauí C. Dermatoscopic findings in telangiectasia macularis eruptiva perstans. An Bras Dermatol. 2013;88:643-5.

122. de Coelho Sousa V, Oliveira A. Inflammoscopy in the diagnosis of hypertrophic lichen planus. J Am Acad Dermatol. 2015;73:e171-3.

123. Suh KS, Han SH, Lee $\mathrm{KH}$, et al. Mites and burrows are frequently found in nodular scabies by dermoscopy and histopathology. J Am Acad Dermatol. 2014;71:1022-3.
124. Kittisak P, Tanaka M. Dermoscopic findings in a case of reactive perforating collagenosis. Dermatol Pract Concept. 2015;5:75-7.

125. Ramirez-Fort MK, Khan F, Rosendahl CO, Mercer SE, Shim-Chang H, Levitt JO. Acquired perforating dermatosis: a clinical and dermatoscopic correlation. Dermatol Online J. 2013;19:18958.

126. Campione E, Diluvio L, Terrinoni A, et al. Severe erythrodermic psoriasis in child twins: from clinical-pathological diagnosis to treatment of choice through genetic analyses: two case reports. BMC Res Notes. 2014;7:929.

127. Bollea Garlatti LA, Torre AC, Bollea Garlatti ML, Galimberti RL, Argenziano G. Dermoscopy aids the diagnosis of crusted scabies in an erythrodermic patient. J Am Acad Dermatol. 2015;73:e93-5.

128. Errichetti E, Lacarrubba F, Micali G, Stinco G. Dermoscopy of Zoon's plasma cell balanitis. J Eur Acad Dermatol Venereol. 2015;. doi:10.1111/jdv. 13538.

129. Lacarrubba F, Nasca MR, Micali G. Videodermatoscopy enhances diagnostic capability in psoriatic balanitis. J Am Acad Dermatol. 2009;61:1084-6.

130. Friedman BJ, Kohen LL. A case of pigmented penile intraepithelial neoplasia: dermoscopic and clinicohistopathologic analysis. J Am Acad Dermatol. 2015;72:S71-2.

131. Ross EK, Vincenzi C, Tosti A. Videodermoscopy in the evaluation of hair and scalp disorders. J Am Acad Dermatol. 2006;55:799-806.

132. Chiramel MJ, Sharma VK, Khandpur S, Sreenivas V. Relevance of trichoscopy in the differential diagnosis of alopecia: a cross-sectional study from North India. Indian J Dermatol Venereol Leprol. 2016; . doi:10.4103/0378-6323.183636.

133. Rakowska A, Slowinska M, Kowalska-Oledzka E, et al. Trichoscopy of cicatricial alopecia. J Drugs Dermatol. 2012;11:753-8.

134. Lanuti E, Miteva M, Romanelli P, Tosti A. Trichoscopy and histopathology of follicular keratotic plugs in scalp discoid lupus erythematosus. Int J Trichol. 2012;4:36-8.

135. Tosti A, Torres F, Misciali C, et al. Follicular red dots: a novel dermoscopic pattern observed in scalp discoid lupus erythematosus. Arch Dermatol. 2009;145:1406-9.

136. Abraham LS, Pineiro-Maceira J, Duque-Estrada B, Barcaui $\mathrm{CB}$, Sodre CT. Pinpoint white dots in the 
scalp: dermoscopic and histopathologic correlation. J Am Acad Dermatol. 2010;63:721-2.

137. Abedini R, Kamyab Hesari K, Daneshpazhooh M, Ansari MS, Tohidinik HR, Ansari M. Validity of trichoscopy in the diagnosis of primary cicatricial alopecias. Int J Dermatol. 2016;. doi:10.1111/ijd. 13304.

138. Nikam VV, Mehta HH. A nonrandomized study of trichoscopy patterns using nonpolarized (contact) and polarized (noncontact) dermatoscopy in hair and shaft disorders. Int J Trichol. 2014;6:54-62.

139. Lacarruba F, Dall'Oglio F, Rita Nasca M, Micali G. Videodermatoscopy enhances diagnostic capability in some forms of hair loss. Am J Clin Dermatol. $2004 ; 5: 205-8$.

140. Rudnicka L, Olszewska M, Rakowska A, Slowinska M. Trichoscopy update 2011. J Dermatol Case Rep. 2011;5:82-8.

141. Duque-Estrada B, Tamler C, Sodre CT, Barcaui CB, Pereira FB. Dermoscopy patterns of cicatricial alopecia resulting from discoid lupus erythematosus and lichen planopilaris. An Bras Dermatol. 2010;85:179-83.

142. Rubegni P, Mandato F, Fimiani M. Frontal fibrosing alopecia: role of dermoscopy in differential diagnosis. Case Rep Dermatol. 2010;2:40-5.

143. Inui S, Nakajima T, Shono F, Itami S. Dermoscopic findings in frontal fibrosing alopecia: report of four cases. Int J Dermatol. 2008;47:796-9.

144. Miteva M, Whiting D, Harries M, Bernardes A, Tosti A. Frontal fibrosing alopecia in black patients. Br J Dermatol. 2012;167:208-10.

145. Fabris MR, Melo CP, Melo DF. Folliculitis decalvans: the use of dermatoscopy as an auxiliary tool in clinical diagnosis. An Bras Dermatol. 2013;88:814-6.

146. Otberg N, Kang H, Alzolibani AA, Shapiro J. Folliculitis decalvans. Dermatol Ther. 2008;21:238-44.

147. Baroni A, Romano F. Tufted hair folliculitis in a patient affected by pachydermoperiostosis: case report and videodermoscopic features. Skinmed. 2011;9:186-8.

148. Rudnicka L, Rakowska A, Olszewska M, et al. Hair shafts. In: Rudnicka L, Olszewska M, Rakowska A, editors. Atlas of trichoscopy. 1st ed. London: Springer; 2012. p. 11-46.

149. Qi S, Zhao Y, Zhang X, Li S, Cao H, Zhang X. Clinical features of primary cicatricial alopecia in
Chinese patients. Indian J Dermatol Venereol Leprol. 2014;80:306-12.

150. Kaliyadan F, Ameer AA. Localized and linear lichen planopilaris over the face and scalp with associated alopecia-clinical and dermoscopy pattern. Dermatol Online J. 2015;21:9.

151. Rakowska A, Slowinska M, Olszewska M, Rudnicka L. New trichoscopy findings in trichotillomania: flame hairs, V-sign, hook hairs, hair powder, tulip hairs. Acta Derm Venereol. 2014;94:303-6.

152. Rudnicka L, Olszewska M, Rakowska A, Czuwara J. Alopecia areata. In: Rudnicka L, Olszewska M, Rakowska A, editors. Atlas of trichoscopy. 1st ed. London: Springer; 2012. p. 205-20.

153. Inui S, Nakajima T, Nakagawa K, Itami S. Clinical significance of dermoscopy in alopecia areata: analysis of 300 cases. Int J Dermatol. 2008;47:688-93.

154. Mane M, Nath AK, Thappa DM. Utility of dermoscopy in alopecia areata. Indian J Dermatol. 2011;56:407-11.

155. Karadağ Köse O, Güleç AT. Clinical evaluation of alopecias using a handheld dermatoscope. J Am Acad Dermatol. 2012;67:206-14.

156. Abraham LS, Torres FN, Azulay-Abulafia L. Dermoscopic clues to distinguish trichotillomania from patchy alopecia areata. An Bras Dermatol. 2010;85:723-6.

157. Inui S. Trichoscopy for common hair loss diseases: algorithmic method for diagnosis. J Dermatol. $2011 ; 38: 71-5$.

158. Inui S, Nakajima $T$, Itami S. Coudability hairs: a revisited sign of alopecia areata assessed by trichoscopy. Clin Exp Dermatol. 2010;35:361-5.

159. Rudnicka L, Olszewska M, Rakowska A. Trichotillomania and traction alopecia. In: Rudnicka L, Olszewska M, Rakowska A, editors. Atlas of trichoscopy. 1st ed. London: Springer; 2012. p. 257-75.

160. Lee DY, Lee JH, Yang JM, Lee ES. The use of dermoscopy for the diagnosis of trichotillomania. J Eur Acad Dermatol Venereol. 2009;23:731-2.

161. Ise M, Amagai M, Ohyama M. Follicular microhemorrhage: a unique dermoscopic sign for the detection of coexisting trichotillomania in alopecia areata. J Dermatol. 2014;41:518-20.

162. Gallouj S, Rabhi S, Baybay $H$, et al. Trichotemnomania associated to trichotillomania: a case report with emphasis on the diagnostic value 
of dermoscopy. Ann Dermatol Venereol. 2011;138:140-1.

163. Peralta L, Morais P. Photoletter to the editor: the Friar Tuck sign in trichotillomania. J Dermatol Case Rep. 2012;6:63-4.

164. Inui S, Nakajima T, Itami S. Scalp dermoscopy of androgenetic alopecia in Asian people. J Dermatol. 2009;36:82-5.

165. Rakowska A, Slowinska M, Kowalska-Oledzka E, Olszewska M, Rudnicka L. Dermoscopy in female androgenic alopecia: method standardization and diagnostic criteria. Int J Trichol. 2009;1:123-30.

166. de Lacharriere O, Deloche C, Misciali C, et al. Hair diameter diversity: a clinical sign reflecting the follicle miniaturization. Arch Dermatol. 2001;137:641-6.

167. Kibar M, Aktan S, Bilgin M. Scalp dermatoscopic findings in androgenetic alopecia and their relations with disease severity. Ann Dermatol. 2014;26:478-84.

168. Hu R, Xu F, Han Y, Sheng Y, Qi S, Miao Y, Yang Q. Trichoscopic findings of androgenetic alopecia and their association with disease severity. J Dermatol. 2015;42:602-7.

169. Rakowska A, Olszewska M, Rudnicka L. Telogen effluvium. In: Rudnicka L, Olszewska M, Rakowska A, editors. Atlas of trichoscopy. 1st ed. London: Springer; 2012. p. 237-44.

170. Slowinska M, Rudnicka L, Schwartz RA, et al. Comma hairs: a dermatoscopic marker for tinea capitis: a rapid diagnostic method. J Am Acad Dermatol. 2008;59:S77-9.

171. Sandoval AB, Ortiz JA, Rodríguez JM, Vargas AG, Quintero DG. Dermoscopic pattern in tinea capitis. Rev Iberoam Micol. 2010;27:151-2.

172. Hughes R, Chiaverini C, Bahadoran P, Lacour JP. Corkscrew hair: a new dermoscopic sign for diagnosis of tinea capitis in black children. Arch Dermatol. 2011;147:355-6.

173. Mapelli ET, Gualandri L, Cerri A, Menni S. Comma hairs in tinea capitis: a useful dermatoscopic sign for diagnosis of tinea capitis. Pediatr Dermatol. 2012;29:223-4.

174. Pinheiro AM, Lobato LA, Varella TC. Dermoscopy findings in tinea capitis: case report and literature review. An Bras Dermatol. 2012;87:313-4.

175. Vazquez-Lopez F, Palacios-Garcia L, Argenziano G. Dermoscopic corkscrew hairs dissolve after successful therapy of Trichophyton violaceum tinea capitis: a case report. Australas J Dermatol. 2012;53:118-9.

176. Hernández-Bel P, Malvehy J, Crocker A, Sánchez-Carazo JL, Febrer I, Alegre V. Comma hairs: a new dermoscopic marker for tinea capitis. Actas Dermosifiliogr. 2012;103:836-7.

177. Neri I, Starace M, Patrizi A, Balestri R. Corkscrew hair: a trichoscopy marker of tinea capitis in an adult white patient. JAMA Dermatol. 2013;149:990-1.

178. Ekiz O, Sen BB, Rifaioğlu EN, Balta I. Trichoscopy in paediatric patients with tinea capitis: a useful method to differentiate from alopecia areata. J Eur Acad Dermatol Venereol. 2014;28:1255-8.

179. Rudnicka L, Rakowska A, Kerzeja M, Olszewska M. Hair shafts in trichoscopy: clues for diagnosis of hair and scalp diseases. Dermatol Clin. 2013;31:695-708.

180. Neri I, Orgaz-Molina J, Ciabatti S, Ricci L, Balestri R. Tinea capitis and dermatoscopy. An Pediatr (Barc). 2014;81:53-4.

181. Koch E, English JC 3rd. Diffuse alopecia in an adolescent female: tinea capitis. J Pediatr Adolesc Gynecol. 2014;27:45-7.

182. Lacarrubba F, Verzì AE, Micali G. Newly described features resulting from high-magnification dermoscopy of tinea capitis. JAMA Dermatol. $2015 ; 151: 308-10$.

183. Wang HH, Lin YT. Bar code-like hair: dermoscopic marker of tinea capitis and tinea of the eyebrow. J Am Acad Dermatol. 2015;72:S41-2.

184. Arrazola-Guerrero J, Isa-Isa R, Torres-Guerrero E, Arenas R. Tinea capitis. Dermoscopic findings in 37 patients. Rev Iberoam Micol. 2015;32:242-6.

185. Lu M, Ran Y, Dai Y, et al. An ultrastructural study on corkscrew hairs and cigarette-ash-shaped hairs observed by dermoscopy of tinea capitis. Scanning. 2016;38:128-32.

186. Schechtman RC, Silva ND, Quaresma MV, Bernardes Filho F, Buçard AM, Sodré CT. Dermatoscopic findings as a complementary tool in the differential diagnosis of the etiological agent of tinea capitis. An Bras Dermatol. 2015;90:13-5.

187. Errichetti E, Stinco G. Dermoscopy as a useful supportive tool for the diagnosis of pityriasis amiantacea-like tinea capitis. Dermatol Pract Concept. 2016;6:13.

188. Kim GW, Jung HJ, Ko HC, et al. Dermoscopy can be useful in differentiating scalp psoriasis from 
seborrhoeic dermatitis. $\mathrm{Br} \mathrm{J}$ Dermatol. 2011;164:652-6.

189. Kibar M, Aktan Ş, Bilgin M. Dermoscopic findings in scalp psoriasis and seborrheic dermatitis; two new signs; signet ring vessel and hidden hair. Indian J Dermatol. 2015;60:41-5.

190. Xu C, Chen D, Liu J, Liu Y, Sun Q. Roles of dermoscopy in the diagnosis and differential diagnosis of scalp psoriasis and seborrheic dermatitis. Zhonghua Yi Xue Za Zhi. 2014;94:3467-70.

191. Verardino GC, Azulay-Abulafia L, Macedo PM, Jeunon T. Pityriasis amiantacea: clinical-dermatoscopic features and microscopy of hair tufts. An Bras Dermatol. 2012;87:142-5.
192. Oxford Centre for Evidence-Based Medicine. "Explanation of the 2011 Oxford Centre for Evidence-Based Medicine (OCEBM) Levels of Evidence (Background Document)". Oxford Centre for Evidence-Based Medicine. Available at: http:// www.cebm.net/index.aspx?o=5653. Accessed 8 August 2016.

193. Aronson JK, Hauben M. Anecdotes that provide definiKve evidence. BMJ. 2006;333:1267-9.

194. Glasziou P, Chalmers I, Rawlins M, McCulloch P. When are randomised trials unnecessary? Picking signal from noise. BMJ. 2007;334:349-51. 